\title{
Getting prices right in structural electricity market models
}

\author{
K.R. Ward ${ }^{(1)}$, R. Green ${ }^{(2)}$ and I. Staffell ${ }^{(1)^{*}}$ \\ (1) Centre for Environmental Policy, Imperial College London, SW7 1NE, UK \\ (2) Imperial College Business School, Imperial College London, SW7 1AZ, UK \\ * Corresponding author: i.staffell@imperial.ac.uk
}

\section{Abstract}

Electricity market models are widely employed to study the role, impacts and economic viability of new technologies. Sources of arbitrage, such as storage and transmission, are increasingly seen as essential for integrating higher shares of variable renewables. Understanding their operation and business case requires models which accurately represent time-series of wholesale electricity prices.

We show that the prevailing assumption of generators bidding short-run marginal cost, such as in the merit order stack, substantially underestimates the spread and volatility of hourly wholesale prices. To compound this, the lack of transparent outputs from previous electricity market modelling studies makes it impossible to scrutinise the prevailing methods or provide a detailed inter-comparison.

We demonstrate a simple modification to the short-run marginal cost approach that delivers improved variability in modelled prices: allowing generators to make a spread of bids, below cost for their first megawatts of capacity, above for their last. Using this model we demonstrate the impact of price variability on the operation and profitability of storage, highlighting the urgent need for greater awareness of this aspect of market model performance.

Keywords: electricity; power systems models; electricity market models; electricity prices; energy storage; transparency; 


\section{Highlights:}

- Energy modelling needs to recognise the value of full model validation

- Price variability is inaccurately represented in electricity market models

- Accurate arbitrage calculations require prices with realistic variability

- Allowing modelled plant bid away from SRMC improves model skill

- Supply curve-based models cannot give accurate price variability

\section{Contents}

Abstract

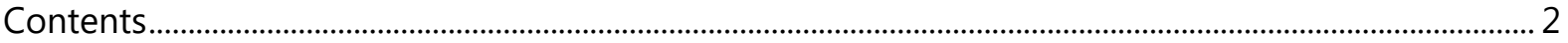

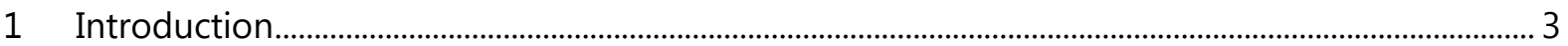

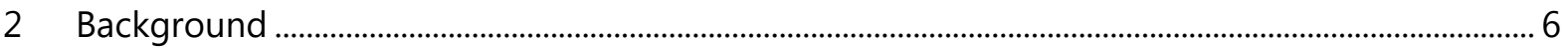

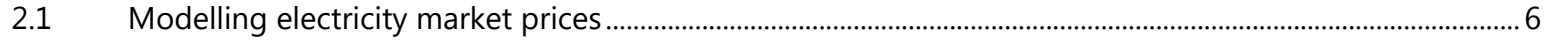

$2.2 \quad$ The British electricity market …………………………………………………………………………………...

3 Data and Methods ...........................................................................................................................10

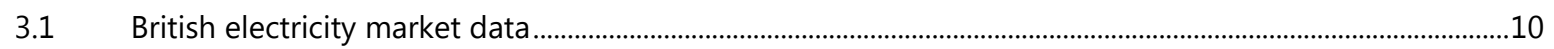

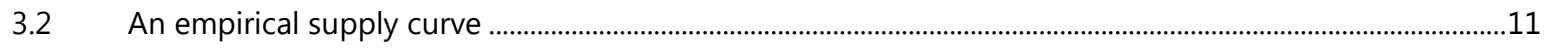

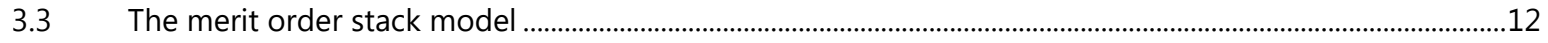

The storage valuation algorithm

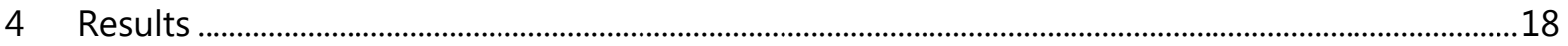

$4.1 \quad$ Benchmarking Model Price Prediction Performance ........................................................................................18

4.2 Benchmarking Model Output Prediction Performance ................................................................................................2

4.3 Small Storage Device Arbitrage Earnings ………………………………………………………………………….....29

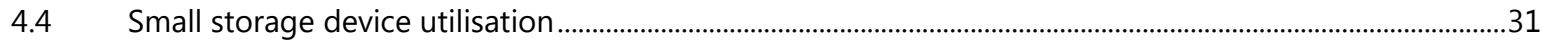

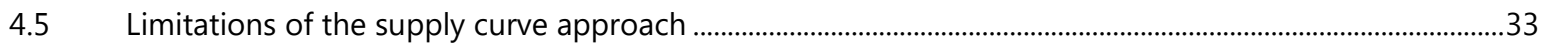

5 Conclusions and Policy Implications.........................................................................................................

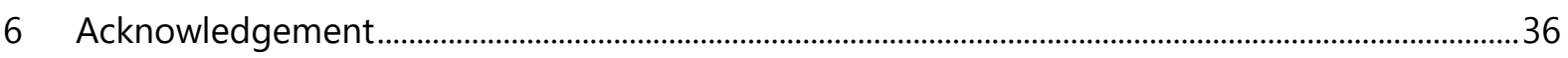

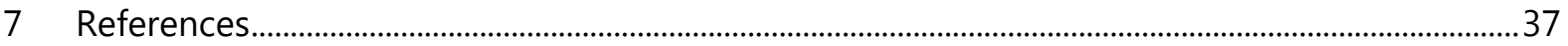




\section{Introduction}

Electricity market modelling is an area of research with substantial societal and policy importance, yet it faces a crisis in transparency and validity [1-3]. There is a growing need for electricity market modellers to consider the extent and realism of the variability in the time-series of artificial prices that models produce. Two emerging technologies - storage and interconnectors - have the potential to earn revenue through arbitrage, which closely links their profitability and utilisation to temporal variations in price. This paper demonstrates that a failure to correctly represent price variability within existing electricity market models will deliver inaccurate estimates of the value and utilisation of these technologies, leading in turn to poor advice to policy-makers and potential investors.

Analytical modelling of prices within deregulated electricity markets plays a central role in guiding the decisions of both market participants and policy-makers across a range of timescales. In Figure 1 the modelled power prices from two widely-published electricity market models are shown. Both are studies of European markets in which day-ahead prices are set by Power Exchanges which ignore sub-national transmission constraints [4], and so the process of balancing expected supply and demand ought to be relatively easy to model. ${ }^{1}$ It is evident that both models struggle to reproduce realistic diurnal variation and the spread of prices observed at the same hour across different days. Other, more complex unit commitment models also appear to insufficiently represent the price variability in real electricity markets, but their results cannot be reproduced here, and these were the only two models for which we were able to find the detailed price data necessary for this analysis. We have intentionally not identified them as this would be to single them out for criticism for what we suspect to be a more widespread failing. Our main point is that, while attention is often paid to a model's skill in determining mean market prices $[3,5-7]$, we have been unable to find examples within the literature in which the temporal variations of model price outputs have been analysed and critically assessed. We therefore suggest that this element of model performance is routinely neglected, and from the examples we have been able to find, it warrants greater attention.

\footnotetext{
${ }^{1}$ In particular, the transmission effects that make it hard to model the Locational Marginal Prices used in the US (inter alia) are not taken into account in the price-setting rules, except via cross-border exports and imports.
} 

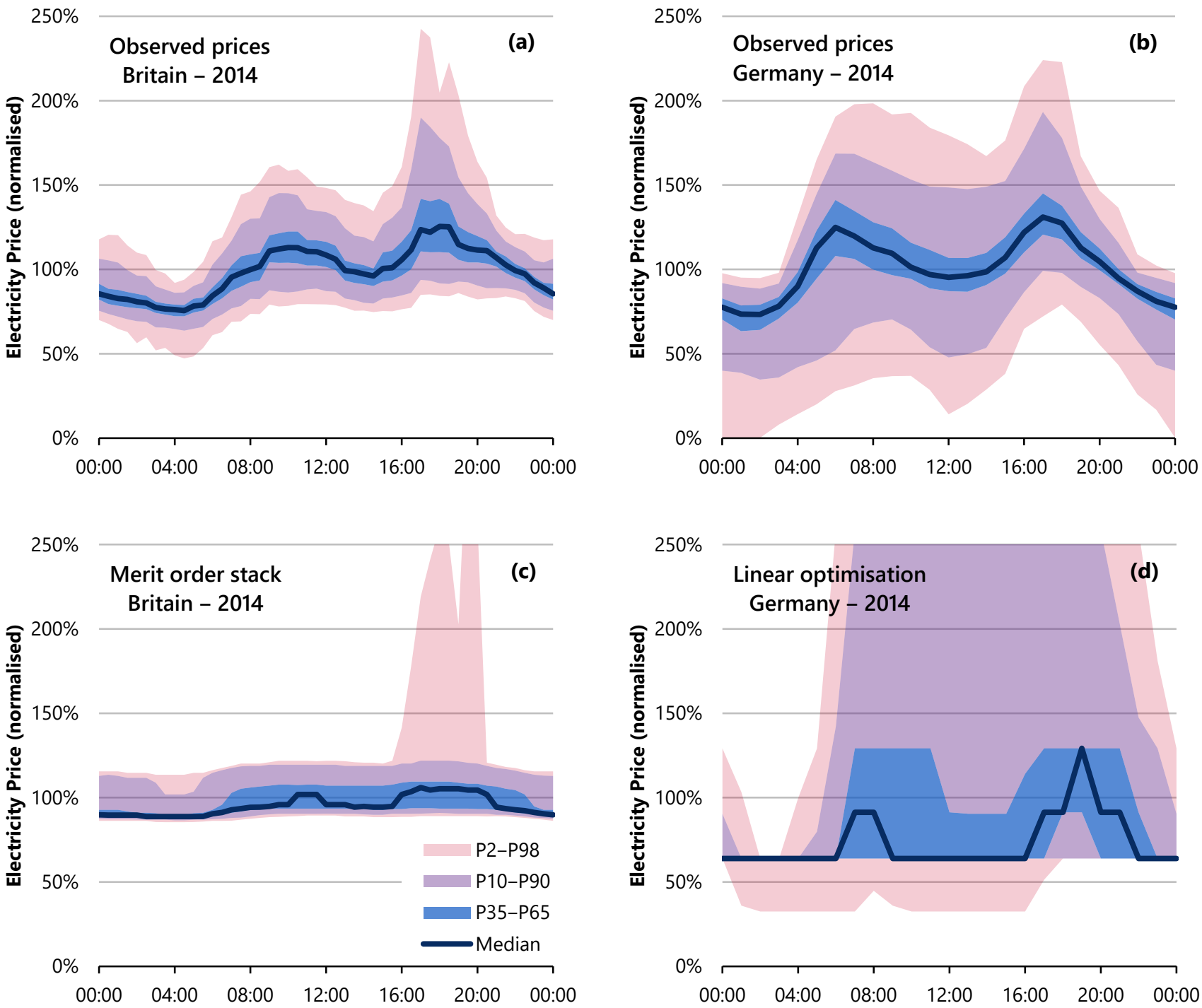

Figure 1: Summary of the diurnal profile and variability of wholesale power prices, highlighting the artificial nature of prices generated by electricity market models. The coloured bands represent the boundaries between the $2^{\text {nd }}, 10^{\text {th }}, 35^{\text {th }}, 65^{\text {th }}, 90^{\text {th }}$ and $98^{\text {th }}$ percentiles. Panels (a) and (b) show historic prices from the British [8] and German [9] markets in 2014. Panel (c) shows the prices generated by a standard merit order stack modelling Britain, as in panel (a). Panel (d) shows the prices generated by a widely-used electricity systems model modelling Germany, as in panel (b).

The importance of reproducing realistic power price volatility within market models extends beyond their relevance to emerging technologies. Efforts to decarbonise electricity systems are disrupting the status quo on both the demand and the supply side in ways that tend to increase price volatility $[8,10]$. Patterns of demand are changing due to growth in electric vehicle use, increased use of electricity for both space heating and cooling and the possibility of dispatchable demand [11-14]. The mix of generation technologies is also changing rapidly [15], for example, the share of weather-dependent renewables in Europe increased ten-fold in the last 14 years. 
Without adequate representation of the characteristics of price variation, the impacts of these changes on incumbent generators may be hard to predict.

In this work we extend a simple merit order stack (MOS) model to create a tool that is able to recreate to a much greater extent the patterns of historic price variability. The changes allow the MOS approach to develop more realistic supply curves, significantly improving the model's skill in representing price variations. This makes it a suitable vehicle for investigating the impacts of price volatility within the market. In this case we have used the model in conjunction with a storage-revenue valuation algorithm to highlight the importance of volatility in in the assessment of storage arbitrage earnings and then adopt a simple LCOS approach to highlight the impact that the revenue inaccuracies might have on future investment decisions.

The work is largely heuristic in nature and we do not seek to explain an underlying economic rationale behind the method described for improving MOS model results. Rather, we see this paper as drawing attention to the significant yet overlooked issue of modelled price variability. The data used in the study is for the UK market, but the method employed can be adapted with equal validity to other markets for which adequate data is available.

The paper is set out as follows. Section 2 gives a brief background to electricity price modelling and forecasting, and sets out some of the key characteristics of the UK electricity market over recent years. Section 3 presents the UK market data, the MOS model, enhancements to the MOS approach and the storage valuation algorithm used. Section 4 examines the properties of the prices produced by the models, their skill in reproducing key metrics for the UK market and describes the comparison of storage valuations from the different price time-series. Section 5 presents conclusions and ideas for future work. 


\section{Background}

\subsection{Modelling electricity market prices}

Interest in modelling and forecasting wholesale electricity prices arose from deregulation of the power industry and the creation of markets for electrical power in many regions of the world, which began in the 1990s.

As Weron [16] identifies, approaches to price modelling have been developed from two distinct perspectives: either electrical engineering or financial modelling. The former, so-called structural market models, have their foundations in the physical processes that determine price, through simulating the dispatch of generators to meet system load with varying degrees of complexity. The latter employ econometric time-series analysis techniques that have been used in the modelling of prices for other commodities. These rely solely on historic prices and are largely disconnected from the realities of generating and distributing electrical power. Hybrid pricing models adapt and combine elements of both these approaches. Many authors have constructed taxonomies of forecasting and modelling techniques, and detailed the methodologies that have been developed over the last 25-or-so years [16-19].

The work presented here focusses on structural models of electricity markets. The fundamental role of an electricity market is to provide a framework in which the supply and demand for electrical power are matched, and a market price for the power is determined.

Figure 2 outlines some of the factors that influence the power prices that markets produce. Depending on the intended use for the model and the timeframe of interest, each of these factors may be either explicitly modelled, parameterised in some way, or ignored. For instance, a model that is focussed on determining the operational dispatch of plant needed to balance supply and adhere to network constraints would require full details of the grid, likely weather conditions on a fine scale, and knowledge of plant ramp rates and rated capacities. On the other hand, a model that is seeking to understand patterns of plant profitability might not need to include a detailed consideration of transmission, balancing and ramping in order to extract the important signals that drive long-term investment decisions. Streamlining the treatment of those elements allows the model to run quickly enough that a range of future scenarios might be investigated. Existing work that uses structural models focuses on the technical aspects (i.e. 
developing sophisticated unit commitment models). This paper aims to complement this by using a technically simple model, which allows for greater treatment of the stochastic elements (i.e. by using 8 years of data with detailed fuel and carbon prices) and a greater focus on the financial elements (i.e. allowing bid prices to deviate from marginal costs).

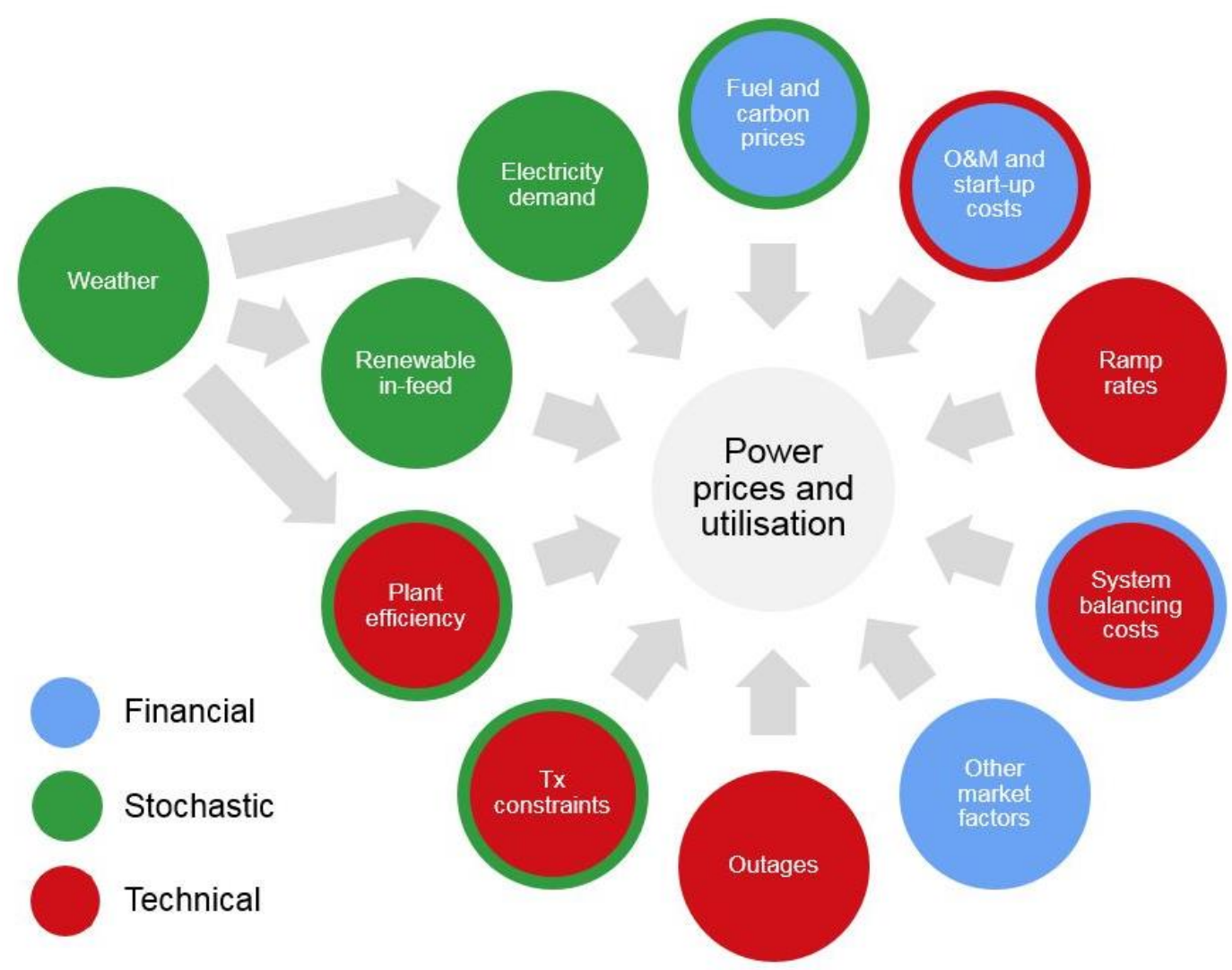

Figure 2: Factors that influence electricity market prices and generator utilisations, separated into broad categories. Borders imply a secondary category for a given input, and stochastic inputs are from the perspective of individual generators (i.e. a single power station takes fuel prices or wider system constraints as exogenous).

One of the simplest treatments of the modelling problem is to consider a grid system unhindered by transmission constraints, without the need for ancillary services (such as reserve and frequency response) and in which the market functions in a truly competitive manner (thereby ruling out strategic bidding practices). In this case, the generators will bid to supply power at their short run marginal cost (SRMC) of operating. SRMCs can be estimated through consideration of plant efficiencies, fuel cost, carbon costs and other operating costs. A merit order is then created, ranking plant so that the cheapest are operated in preference to more expensive plant, allowing a supply curve to be developed from the aggregated bids of the suppliers. This is the basis of the merit order stack (MOS) approach. The relative simplicity of this approach can be justified since system balancing, constraints and all ancillary services accounted for only around $1 \%$ of final 
electricity bills in Britain and Germany, compared to electricity generation which accounts for 40$45 \%$ of the cost [20]. From the materiality principle, it makes sense to focus greater attention on modelling the price formation of bulk electricity production, as much existing work has been dedicated to the ancillary markets.

From a modelling perspective, the supply curve provides a method by which a given time-series of electricity demands may be mapped to a new time-series of electricity prices. The curve will vary over time as capacities and SRMCs change due to plant availability, fuel price, weather, $\mathrm{CO}_{2}$ prices, emissions constraints etc. The key simplification of the MOS approach is to treat the short run average variable cost (SRAVC) - the fuel and variable operating costs incurred over a period such as a quarter, divided by the plant's output over the same period - as the SRMC.

Moving beyond the conceptually simple starting point of the MOS, many layers of complexity may be added, for example, technical restrictions on plant operations such as maximum ramp rates or minimum outputs, start-up costs and modelling of the grid to assess transmission considerations. But even full unit commitment models, which attempt to simulate the entire generation and distribution network with great physical detail, still rely upon establishing a mapping between demand and cost in the way described above.

The factors in Figure 2 that introduce volatility into electricity prices are:

- Volatility in demand

- Volatility in supply - either through stochastic events such as unexpected outages or, increasingly, due to weather

- Issues in the transmission network that require the merit order to be ignored

- Ramping of plant

- Strategic bidding practices

- Volatility in fuel prices (less so though as mostly generators do not buy fuel on spot markets))

What is apparent is that the processes that drive volatility occur on short timescales and are therefore unlikely to be captured by a simple model that is streamlined to run quickly. Historically, this may not have mattered much but, for the reasons outlined in Section 1 , this is no 
longer the case and we need to extend the simplified approaches so that they maintain relevance. This paper will suggest one possible approach to solving this problem.

\subsection{The British electricity market}

Figure 3 shows the distribution of historic prices in the British wholesale market for each year since 2010. The increase in price variability in the last two years is marked. Previously, the prices during the middle 8,560 hours followed a consistent distribution with variation in only the top 100 and bottom 100 half-hour periods. Now it appears this variability is expanding both the top end and, more markedly, at the bottom end, creating more revenue for arbitrage. The mean price has remained reasonably similar (in the range of $£ 39-51 / \mathrm{MWh}$ ) but the standard deviation has increased dramatically (from $\pm £ 13 / \mathrm{MWh}$ in $2010-15$ to $\pm £ 24$ in 2016).

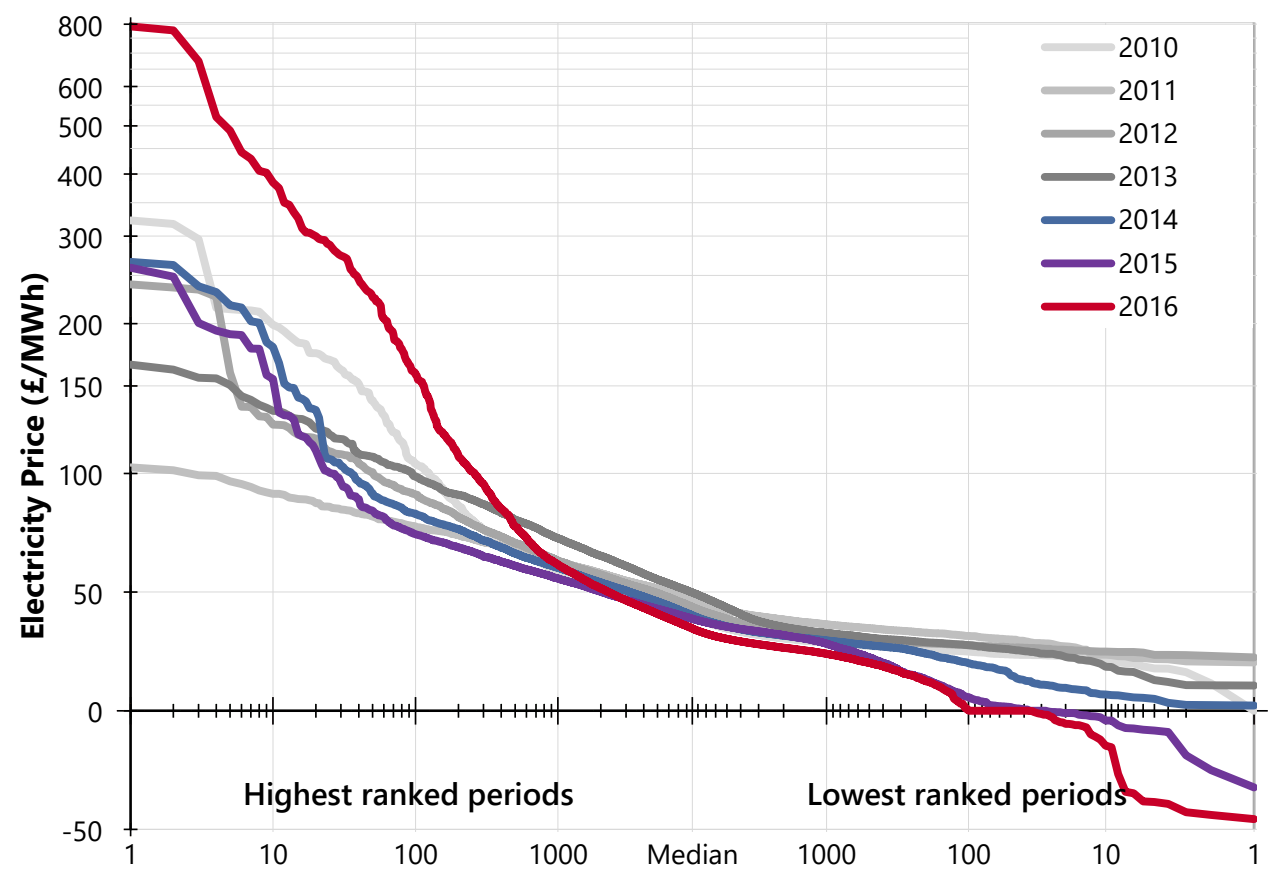

Figure 3: Price-duration curves showing the day-ahead price in Britain for each year from 2010 to 2016.

The highest and lowest prices are shown at the edges which converge towards the median on logarithmic axes to highlight the extreme prices.

The increased market penetration of wind and solar power in particular has produced discernible impacts on the volatility and range of daily electricity prices in many countries $[10,21]$. This can be seen for Britain in Figure 3, most notably in the emergence of periods of negative electricity prices. 


\section{Data and Methods}

In the first part of this study we develop a revised merit order stack model, which is modified so as to improve its skill in reproducing variability in the time series of power prices that it outputs. The first part of this section (Section 3.1) describes the data upon which this model is based. In Section 3.2 the concept of an empirical supply curve is introduced, which is used as a benchmark for assessing the performance of the new model. The merit order stack model is described in Section 3.3. The second part of the study uses this new model to assess the impact of the temporal variability of modelled electricity prices on the estimates of the revenues that may be earned by a small (1MW maximum power) storage device. This is achieved through modifying a simple MOS model for the UK so that the supply curve that it produces can be systematically adjusted, altering the volatility of the prices that it produces. The algorithm used to evaluate storage earnings is described in Section 3.4.

\subsection{British electricity market data}

We use the British electricity market as a case study to illustrate the significant effect that price volatility has on estimates of potential arbitrage earnings. This analysis could be replicated in other regions with sufficient data, and we believe that the message is relevant to models of other competitive electricity markets.

This study focusses on the period 2009-2016 for which historic price, demand and plant utilisation data are freely available. The half-hourly output of different generator types was taken from Elexon via [22], and was augmented with data on inflows from interconnectors, pumped storage and unmetered renewables from National Grid [23]. The output from wind, solar, interconnectors and hydro was subtracted from demand for the purposes of modelling the output from thermal plants only. Half-hourly wholesale electricity prices were also taken from Elexon as in [22]. Quarterly-average carbon prices were taken from [24, 25], accounting for British power stations paying the European Emissions Trading Scheme (ETS) market price plus the UK Government's Carbon Price Floor (CPF) introduced in 2013 to top this up.

Quarterly-average fuel prices for power stations were taken from [26]. The temporal resolution of this data will likely smooth the variability in prices purchased on the spot markets for on-theday operating decisions. 
Inputs to the modelling process were: fuel and carbon prices, and the profile of net demand to be met by power stations that are dispatched on a purely economic basis (i.e. not constrained by weather or incentivised to run baseload due to subsidies). For this, we used demand net of interconnectors, storage, intermittent renewables and biomass. Biomass was netted off as the majority of plants in the UK are currently supported by Contracts for Differences, and so their operating patterns are not determined by pure wholesale prices [8]. The data against which the model outputs were validated were the generation mix for fossil plants and wholesale prices.

The installed capacity of power stations was time-varying with quarterly averages, to reflect the dramatic reduction in fossil-fuelled capacity seen over the eight-year period considered. This capacity was modelled in at the granularity of individual power stations (i.e. plant-wise rather than technology-wise) using proprietary data provided by Bloomberg New Energy Finance (BNEF) [27]. This dataset provides the capacity and efficiency of each thermal power station, derived by BNEF based on plant age, technology, and calibrated against market data. This dataset was reduced down to 17 technology groups by aggregating plants whose efficiency deviated by less than $0.2 \%$. No other distinguishing characteristics (such as plant-specific operation and maintenance costs) were available, and so this reduction had no discernible impact on model granularity.

\subsection{An empirical supply curve}

As mentioned in Section 2.1 the merit order stack approach conceptually reduces the power system to a single supply curve, as there are no inter-temporal constraints to restrict generator availability, and no additional factors (such as start-up costs) which can move electricity prices away from short-run average costs. The merit order stack therefore acts as a function mapping a demand for power to a single price at which the power can be supplied.

If real power systems could be reduced to a single mapping function, then one could divine it by ranking all observed power price data and plotting them against the ranked observed demands. We have applied this approach to quarterly datasets for Great Britain, and used the resulting empirical supply curves to produce a new set of demand-based prices for each quarter. The time-series of these prices obviously differ from observations in the order in which the prices occur, but the population statistics will be identical. Essentially, using the empirical supply curve to in calculations for arbitrage is the best that a single supply curve model, such as the MOS, 
might achieve. These empirically derived supply curves are used for comparison with the MOS curves and are also used to produce time-series of prices for the storage algorithm.

\subsection{The merit order stack model}

The model used in this work is based on an extension of the merit order stack approach. This basic model is described in [22], and an overview is given in the supplementary material. In summary, the SRMC of plant type $g$ is calculated according to Equation 1 :

$$
\mathrm{SRMC}_{(\mathrm{g})}=\text { Carbon }_{(\mathrm{g})}+\text { Fuel }_{(\mathrm{g})} / \eta_{(\mathrm{g})} \quad \text { Equation } 1
$$

Where Carbon $_{(g)}$ is the cost of carbon emissions and Fuel $(g) / \eta_{(g)}$ are the fuel costs. The Operational costs are included in an adjusted plant efficiency as described in Section 3.1. This model produces a supply curve with 18 possible prices (one for each of the 17 plant-types plus the price when wind is curtailed). A supply curve for a sample quarter (Q1 2011) is shown in Figure 4. The most important feature to note is the small range of prices that this model will deliver in response to changes in demand. The blue shaded area denotes the range in which $90 \%$ of the quarter's power demand lies $(30.5-51.2 \mathrm{GW})$. $90 \%$ of the prices produced by the supply curve from this simple MOS model will lie in the range $£ 41.77$ to $£ 44.52$. In fact the observed P5-P95 range for Q1 2011 was $£ 38.35-£ 65.56$.

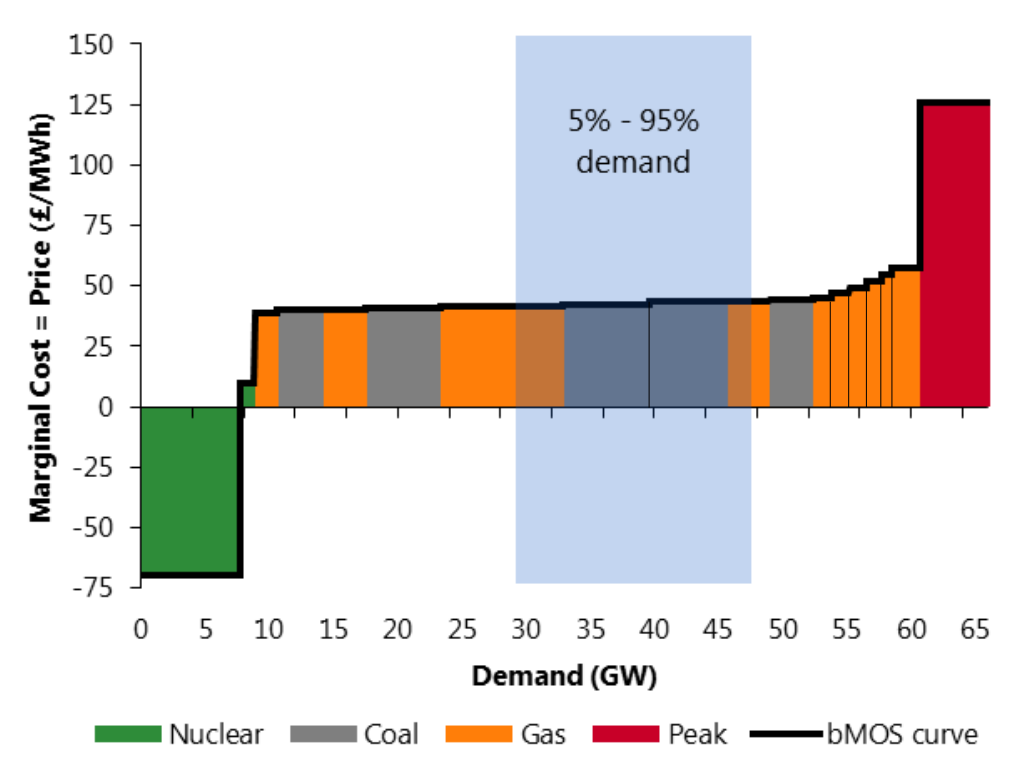

Figure 4: The merit order stack and supply curve generated by the basic MOS model. The shaded area indicates the P5-P95 range of electricity demand.

In order to progress we need to find a way to include the aggregated effects of those volatilityproducing factors that we have deliberately omitted from our model in order to secure a fast running time. Figure 5 (left panel) shows the empirical supply curves obtained from observed 
data for the UK electricity market for the first quarters of the years 2009 - 2016. Considerable variability exists between quarters, which is not reduced through scaling by mean price or through consideration of the demand in terms of total available capacity. However, the curves do exhibit similar characteristics which are captured by the schematic in the right hand panel. The MOS supply curve for Q1 2011, discussed above, is shown in black dash, with the observed empirical supply curve shown prominently in black.

The MOS curve is derived by assuming that generators bid at their SRMC, and the data used in the model accurately reflects conditions within the UK market at that time. The discrepancy therefore suggests that, rather than placing bids at or around the mean price/ SRMC, generators are more flexible in the prices at which they offer to sell power - often selling at less than cost, and sometimes at considerably more. With this in mind, our approach takes each plant type, sub-divides it further into nine tranches and then allows each tranche to bid into the stack at prices that deviate from the SRMC by a specified amount, as summarised by Equation 2 and 3, and described in full in the supplementary material. We refer to this process as price spreading.

$$
\begin{array}{rlr}
\operatorname{Bid}(g, i) & =\operatorname{SRMC}_{(g)}+\sigma^{*} \operatorname{Tranche~Adjustment}_{(g, i)} & \text { Equation 2 } \\
\text { Tranche Adjustment }(g, i) & =\alpha_{(g)} * \boldsymbol{F}(i) *\left(\operatorname{Carbon}_{(g)}+\operatorname{Fuel}_{(g)} / \eta_{(g)}\right) & \text { Equation 3 }
\end{array}
$$

Where $\operatorname{Bid}(g, i)$ is the bid price of the ith tranche of generator type $g, \operatorname{SRMC}(g)$ is the short run marginal cost of generator type $\mathrm{g}$ from the original MOS model and $\mathrm{F}(\mathrm{i})$ is a vector quantity specifying the extent of the deviation from the SRMC. $\alpha(\mathrm{g})$ is a variable that allows differing amounts of spreading according to plant type as we found that the performance of this approach improved if we allowed the extent of variation from SRMC to vary for coal and gas generators. $\sigma$ is used in order to vary the amount of variability within the prices for the study of the impact of this on arbitrage earnings of storage.

The right panel of Figure 5 visualises this process. The orange-shaded areas highlight the fact that we have no knowledge of what bids were made by either baseload plant that always runs or peaking plant that is never called upon to run. Since the positioning of the maximum baseload and maximum capacity is variable, the end points of the empirical supply curve may move left and right. Changes in maximum and minimum prices in each quarter also mean that the end points can move up and down. The shaded tranches indicate how this approach can be used to fit to the shape of the empirical supply curve using 9 blocks. 

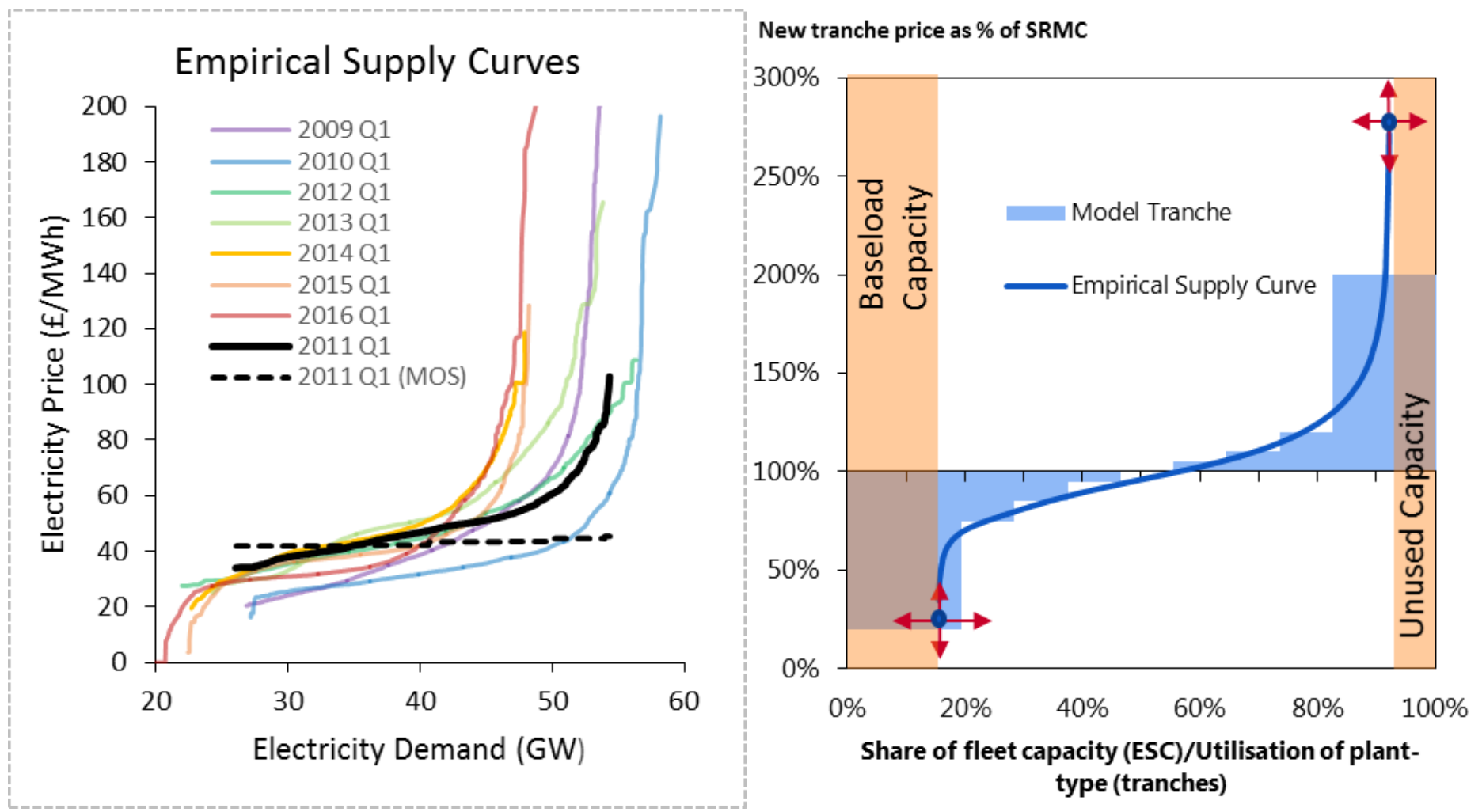

Figure 5: Empirical supply curves observed in the British electricity market, and a method for converting these into model tranches. The left hand panel shows the empirical supply curves obtained by ranking quarterly demand and quarterly power prices. The right panel shows a schematic for converting a quarter's supply curve into model tranches.

When this technique is applied to the MOS for Q1 2011, the stack of Figure 4 is transformed using the tranches of Figure 5, as shown in Figure 6: first into Figure 6a and then re-sorted as in Figure 6b. Conceptually, this strategy reflects the fact that, over a quarter, any individual plant's bidding strategy might sometimes lead it to bid below SRMC (if, for instance demand is low and it is desirable not to shut down) and at other times to bid above SRMC (for example if demand is high and there is a belief that it (and competing generators) can command scarcity rent through higher prices). 

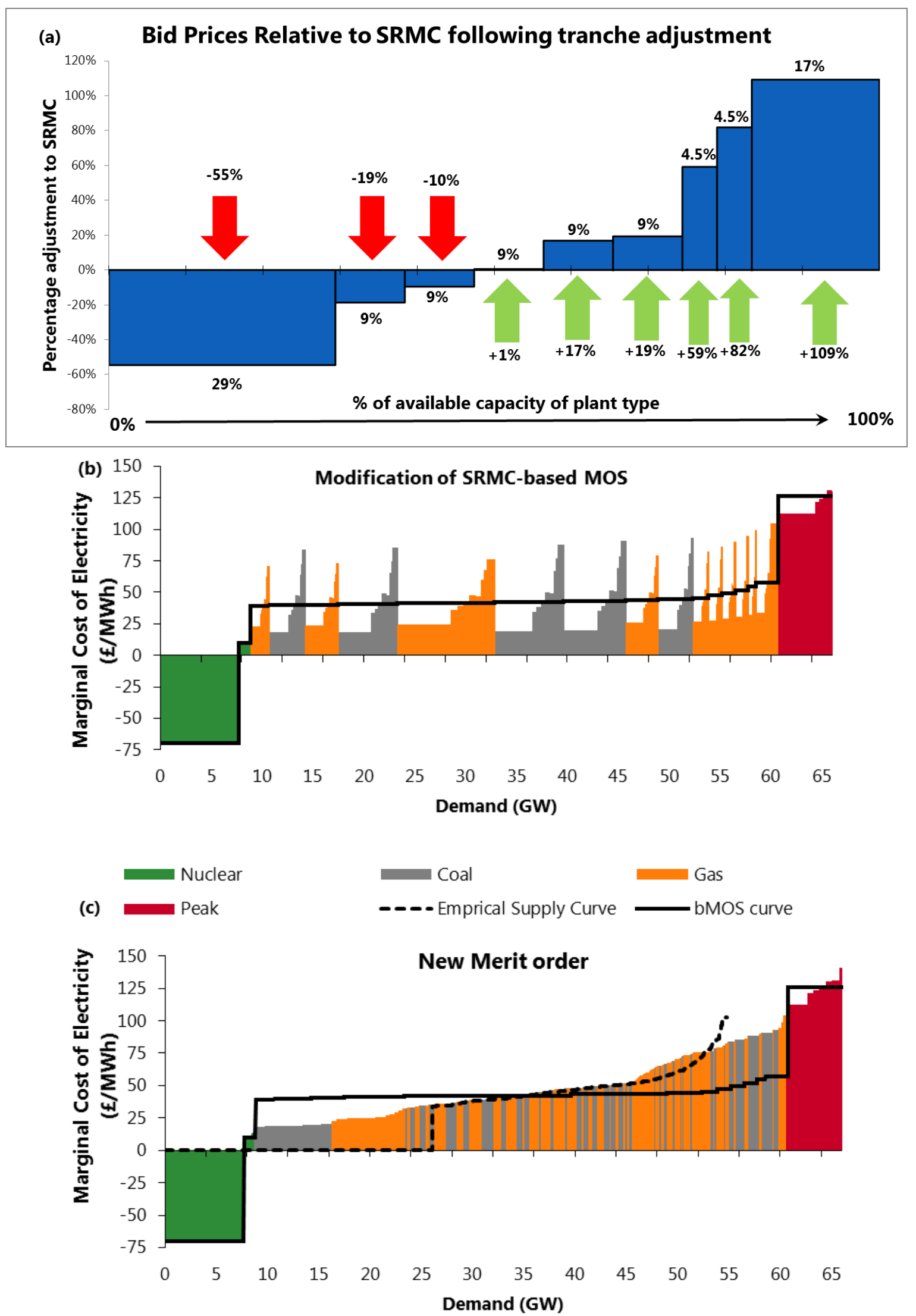

Figure 6: Development of the enhanced merit order stack model. Panel (a) shows the profile of the tranche parameters used to adjust the SRMCs for each generator type Panel (b) illustrates the modifications as applied to the SRMCs. Panel (c) gives the re-ordered stack and shows the empirical supply curve for the same quarter (Q1 2011). 
This produces a model with 19 parameters -9 tranche widths and 9 corresponding tranche adjustments plus the multiplicative parameter, $\alpha$, describing the ratio between coal and gas spreading amounts. To optimise their values, we took 5,000 random draws from the parameter sets defined in the supplementary material (Table S1). Each set of parameters was then used to produce a stack for each quarter within the dataset, and this in turn was used to produce simulations of the half-hourly market prices and outputs of coal- and gas-fired power stations.

In order to gauge the performance of the parameter sets, the modelled prices and outputs were compared to observed values as follows. Both the modelled and observed prices and gas and coal outputs were sorted into ascending order. The root mean square difference between these sorted modelled and observed series, taken over all 4400 half-hours, was calculated for each quarter. We are thus able to select the set of parameters that gives optimal agreement for price, or for output or to select a compromise solution. The decision was taken to use this Monte-Carlo approach due to the fast run time of the model, which allows the parameter space to be trawled effectively in this way.

The potential for predicting the choice of tranche parameters from fundamental market data is discussed in the results section. This approach may be applied to other model formulations and power systems provided only with data on prices and output by generator class - which is available in most European power systems and American markets.

\subsection{The storage valuation algorithm}

To evaluate the potential earnings of the storage device we have employed the profit-maximising storage dispatch algorithm which is described in [28], and based upon previous works [29-31]. This algorithm optimises storage operation for a given time-series of prices to maximise arbitrage earnings, and uses the supply curves generated by the MOS models to account for the impact that storage output would have on power prices (reducing peaks and raising troughs), thus assessing the potential revenue of larger storage devices.

A full description of the algorithm is presented in [28]. In brief, it takes a time series of power prices (in this case for each half-hour period within a quarter) and pairs time periods of low price (for charging the device) with those of high price (for discharging). It accounts for constraints of device charge rates and maximum and minimum charge levels to develop an operation schedule 
for the device that will optimise its profits. For a small device (c. 100MW within the 50-60GW peak GB system) it is unnecessary to consider the impact of its operation on system power prices, as the volumes of electricity bought and sold are too small to effect a significant change in demand. For larger devices, the algorithm iterates the deployment of storage in a series of small steps, each of which is too small to introduce significant errors in the calculation of an optimal dispatch, and recalculates system prices from the supply curve between each iteration [28].

We consider three storage technologies: Lithium ion, sodium-sulphur and redox flow. The technical specifications of the storage are given in Table 1 , and the maximum power output is 1 MW. In addition, the initial charge on the battery is $50 \%$ of full charge and the storage model parameter that allows for a marginal cost of (dis)charge is set to $0 \mathrm{f} / \mathrm{MWh}$.

\begin{tabular}{lcc}
\hline Technology & $\begin{array}{c}\text { Round-trip } \\
\text { efficiency (\%) }\end{array}$ & $\begin{array}{c}\text { Discharge } \\
\text { duration (hours) }\end{array}$ \\
\hline Lithium-ion & $86 \%$ & 3 \\
Redox-flow & $73 \%$ & 6 \\
Sodium-sulphur & $81 \%$ & 7 \\
\hline
\end{tabular}

Table 1: Technical specifications of the storage technologies, based on [32].

The impact of price volatility on the arbitrage earnings of the storage device is assessed by varying the magnitude of the price spreading applied (parameter $\sigma$ in Equation 1), which is an excellent proxy for the standard deviation of the resulting modelled prices $\left(R^{2}=0.95\right.$ averaged over the 32 quarters), though the relationship breaks down at very low values of spreading in some quarters. The price-optimised MOS model is used as we are interested only in the deployment of the storage and not on the wider issue of how electricity demand is met. If we were looking at the deployment of large amounts of storage, such that there was a material impact on prices and the deployment of other generators, then it would be most appropriate to use the compromise MOS to model these effects. Since the device is small, it is also possible to compare the arbitrage earnings with those that are obtained using historical price time series (since deployment will have a negligible effect on market prices). The empirical supply curve offers another point of comparison: it will have the same standard deviation as the observed prices, though the ordering will differ since the prices will strictly be related to the demand only. 


\section{Results}

As described in Section 3.3 the parameters used in this modelling study were obtained through stochastically testing thousands of possibilities and choosing those values that gave the best results according to the criteria applied - skill at predicting prices (price-optimised), skill at predicting plant output (output-optimised) or a combination of the two (compromise). Figure 7 takes two quarters, representing differing behaviours, and plots the price and output metrics obtained for each set of parameters sampled. The results for Q4 2009 deliver optimal price and optimal output solutions that lie far apart. A compromise solution performs acceptably well against both criteria, but we plan further research (as well as further searches of parameter space) in the hope of improving this. In contrast, the results for Q1 2011 show optimal solutions that are closely matched and parameters that perform well against the price metric also perform well against the output metric.

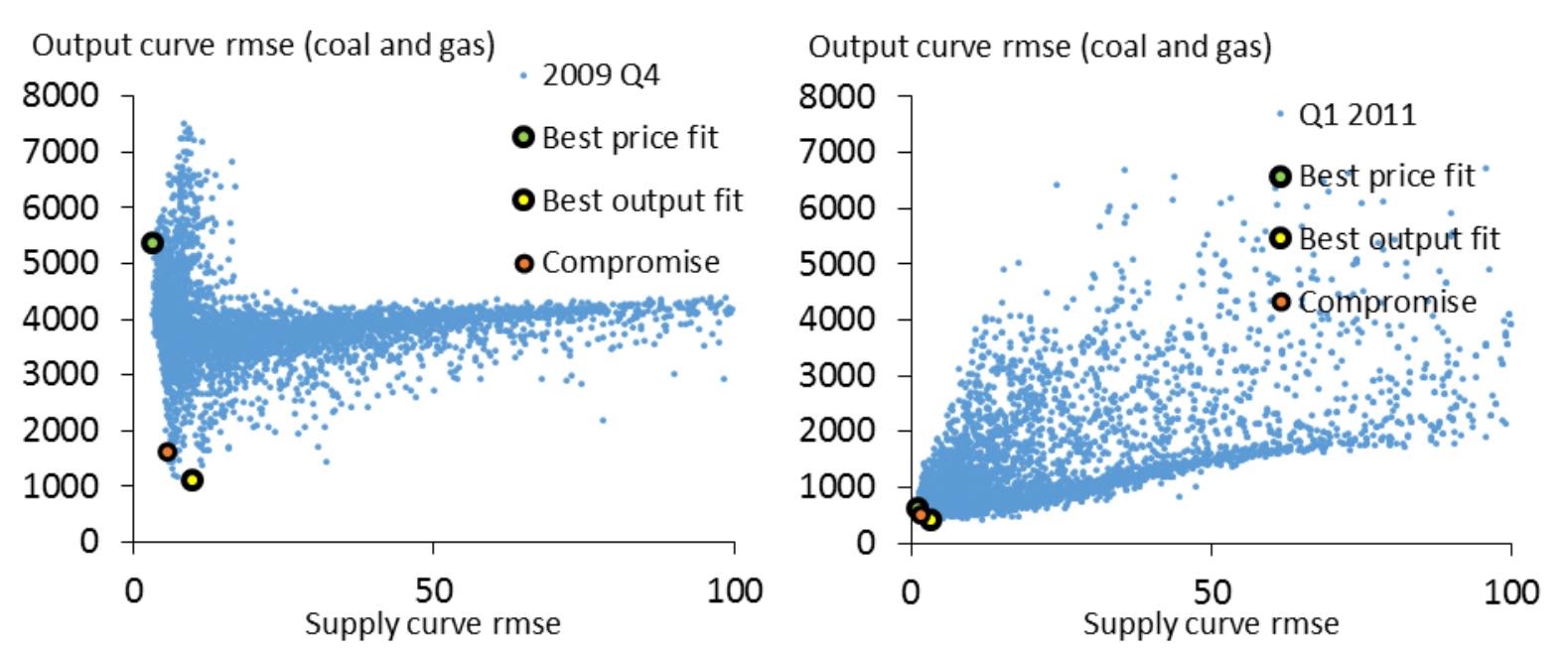

Figure 7: Plots the two metrics used to measure model skill for two individual quarters. Each panel shows the root mean square error (RMSE) of the modelled supply curve relative to the empirical supply curve (i.e. divergence of power prices, in $\mathrm{f} / \mathrm{MWh}$ ) plotted against the average RMSE of the modelled gas and coal output-duration curves relative to the observations (i.e. the divergence in hourly generator utilisations, in MW). In each panel, the cloud of points shows each set of sampled parameters. The optimal choices for each quarter are indicated.

\subsection{Benchmarking Model Price Prediction Performance}

Figure 8 and Figure 9 and Table 2 compare the mean prices produced by the no-spreading, price-optimising, output-optimising and compromise approaches with the observed behaviour of the UK market over the period 2009-2016. 
a: MOS model without price spreading

Wholesale Price ( $\mathrm{f} / \mathrm{MWh}$ )

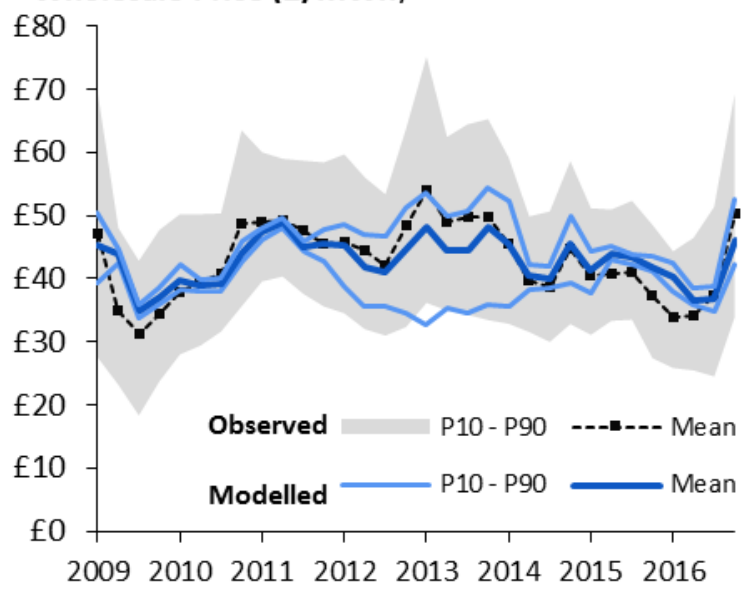

c: Output-optimised price-spreading MOS model

Wholesale Price (f/MWh)

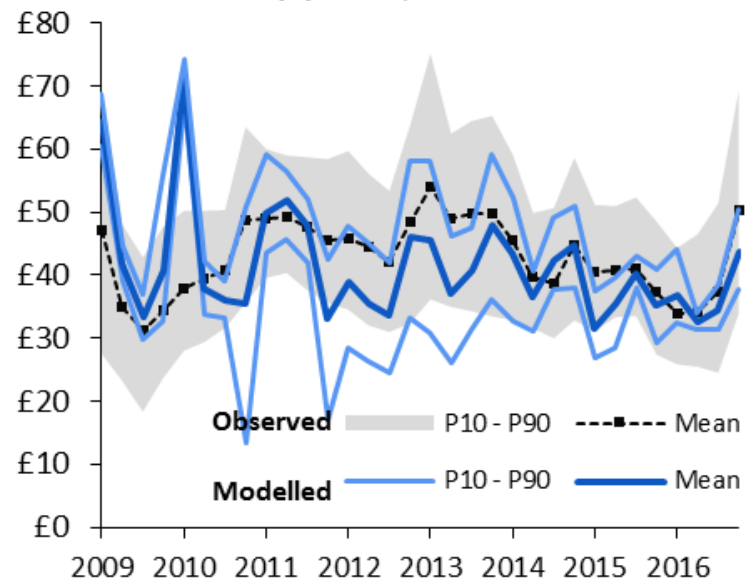

b: Price-optimised price spreading MOS model

Wholesale Price ( $\mathrm{f} / \mathrm{MWh}$ )

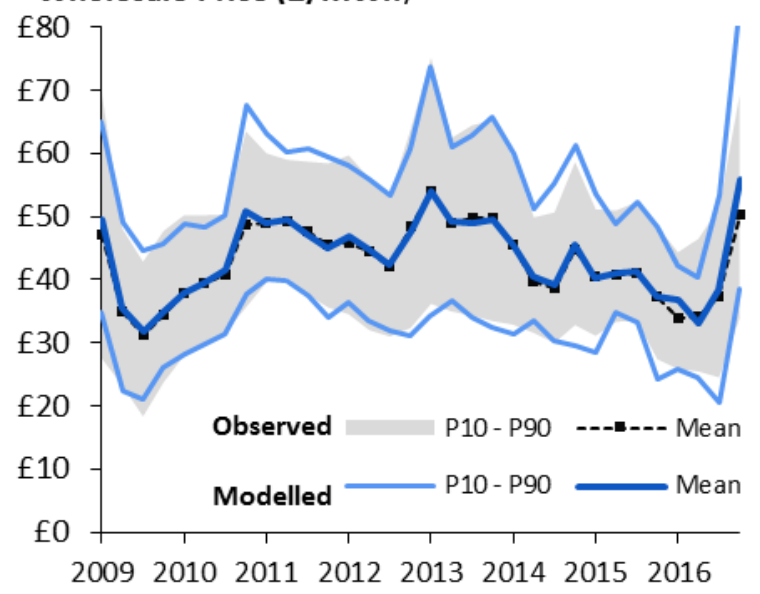

d: Compromise price spreading MOS model

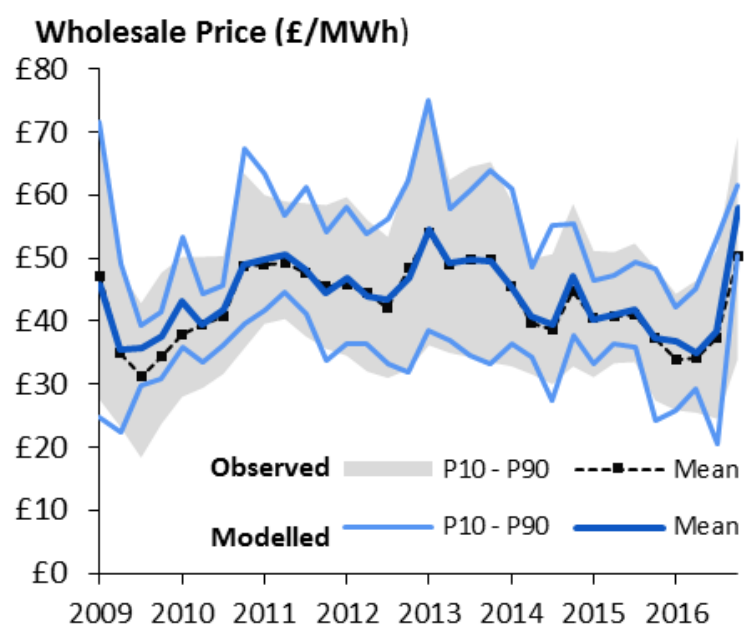

Figure 8: Comparison of the quarterly wholesale prices from the 4 variants of MOS model with the actual market prices for the period 2009 - 2016. The time-series of prices give the mean, $10^{\text {th }}$ and $90^{\text {th }}$ percentiles in each quarter. The shaded area and dotted line show historic data, the solid lines show the models' output. 
a: MOS model without price spreading

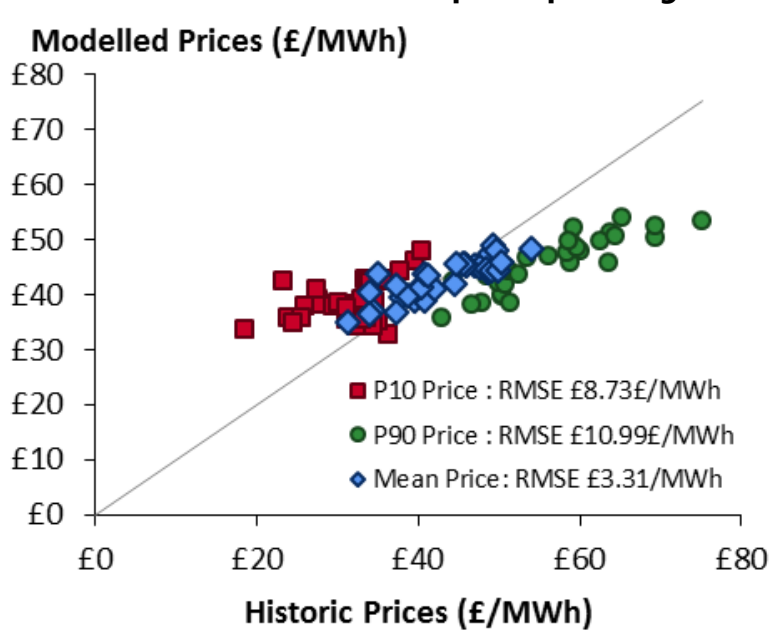

c: Output-optimised price-spreading MOS model Modelled Prices ( $\mathrm{f} / \mathrm{MWh}$ )

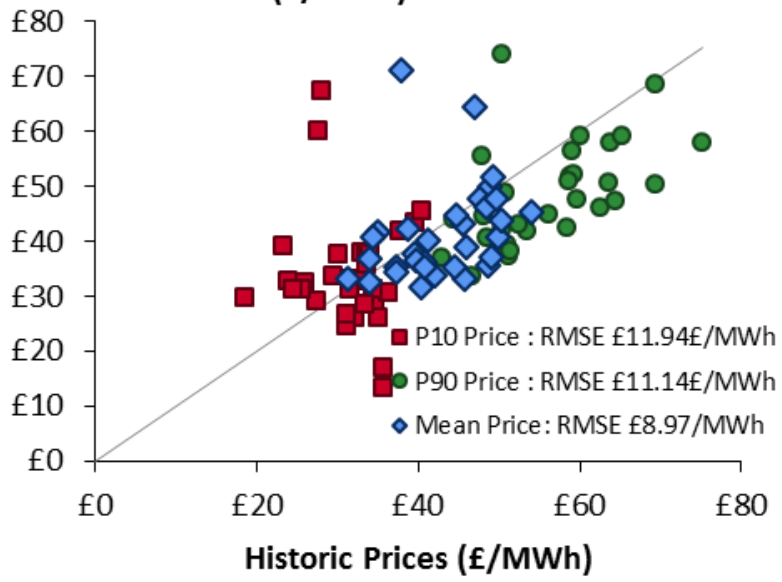

b: Price-optimised price spreading MOS model

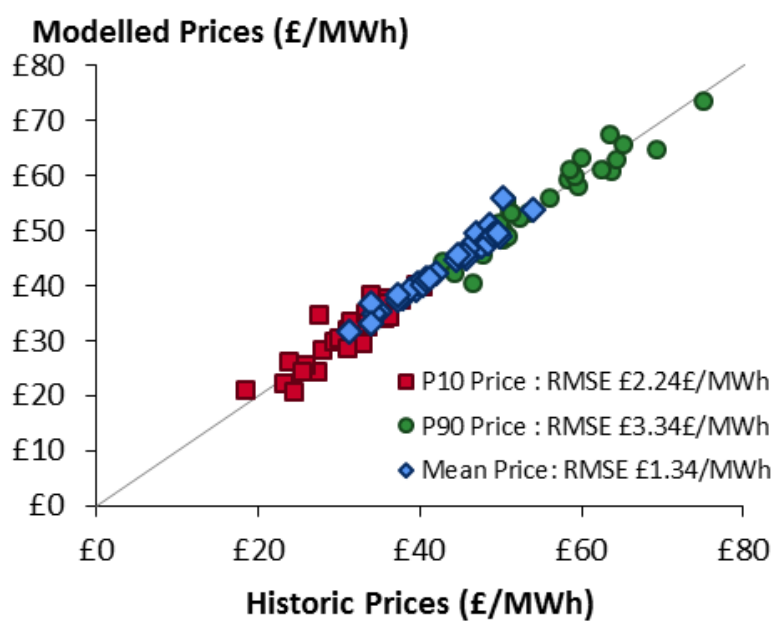

d: Compromise price spreading MOS model

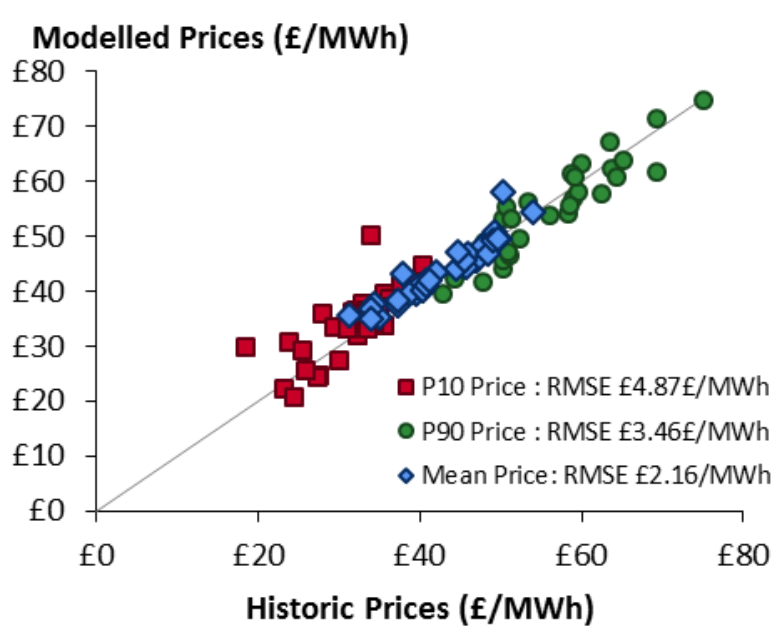

Figure 9: Correlation between the historic and modelled quarterly price data shown in Figure 8.

\begin{tabular}{lccccc}
\hline Metric & $\begin{array}{c}\text { Observed } \\
\text { Prices }\end{array}$ & $\begin{array}{c}\text { No } \\
\text { Spreading }\end{array}$ & $\begin{array}{c}\text { Price- } \\
\text { Optimising }\end{array}$ & $\begin{array}{c}\text { Output- } \\
\text { Optimising }\end{array}$ & Compromise \\
\hline Mean price & $£ 42.91$ & $£ 42.80$ & $£ 43.40$ & $£ 41.41$ & $£ 43.94$ \\
$10^{\text {th }}$ percentile price (P10) & $£ 31.30$ & $£ 38.73$ & $£ 31.50$ & $£ 34.07$ & $£ 33.95$ \\
$90^{\text {th }}$ percentile price (P90) & $£ 55.95$ & $£ 45.81$ & $£ 56.33$ & $£ 48.34$ & $£ 54.65$ \\
RMSE mean prices & - & $£ 3.31$ & $£ 1.34$ & $£ 8.97$ & $£ 2.16$ \\
RMSE P10 prices & - & $£ 8.73$ & $£ 2.24$ & $£ 11.94$ & $£ 4.87$ \\
RMSE error P90 prices & - & $£ 10.99$ & $£ 3.34$ & $£ 11.14$ & $£ 3.46$ \\
Gradient of regression line & - & $35 \%$ & $101 \%$ & $46 \%$ & $92 \%$ \\
observed vs model & & & & &
\end{tabular}

Table 2: Measures of the predictive performance of power prices (in $\mathrm{f} / \mathrm{MWh}$ ) from the basic, priceoptimising, output-optimising and compromise MOS models. RMSE = root mean square error

With the simple inputs of just fuel price, demand, plant availability and efficiency data, the basic MOS model does a reasonable job of recreating the broad behaviour of UK electricity prices. The mean quarterly system price (Figure $8 \mathrm{a}$ ) is close to that observed (42.80 f/MWh cf $42.91 \mathrm{f} / \mathrm{MWh}$ ), 
and we note that it is the annual or multi-year average price that most models in the literature are validated against $[22,33]$. However, the variability exhibited by these modelled prices is significantly less than is seen in the observations, with a P10-P90 range of 7.08 $\mathrm{f} / \mathrm{MWh}$ compared to $24.65 \mathrm{f} / \mathrm{MWh}$ (Table 2). This is visually obvious from both Figure $8 \mathrm{a}$ and Figure $9 \mathrm{a}$.

The price-optimised MOS with price spreading model (Figure $8 \mathrm{~b}$ and Figure 9b) achieves excellent agreement with observed prices. The mean is a little high at $43.40 £ / M W h$, but in all other metrics the price characteristics of the UK market are closely matched. Figure $8 \mathrm{c}$ and Figure $9 c$ relate to the MOS model that was optimised against plant output. The poor performance in replicating system prices confirms what was noted above about the need to trade-off price and output performance in some quarters. The model's skill in reproducing the output of gas and coal generators in discussed in the next section. Finally, in Figure $8 \mathrm{~d}$ and Figure $9 d$ we see the compromise solution, which produces a very reasonable representation of the price characteristics of the market, only struggling to reproduce observations in 2009 and early 2010 .

By considering the percentile characteristics of the model performance, the above metrics offer an expanded picture of the quarterly price behaviour compared what with what is usually provided. However, we can extend this further, both by considering the distribution of halfhourly prices and by comparing the supply curve with the empirical supply curve shown in Figure 5.

Figure 10 presents a histogram of the normalised prices for the entire study period, allowing greater insight into the ability of the two MOS methods to produce realistic price distributions. As it only has 18 possible system prices to call upon in any given quarter, the MOS model without price spreading (left hand plot) produces a small number of discrete system prices, which cluster tightly around the model mean. The 154 possible system prices within the MOS with spreading, coupled with the optimal choice of parameters in each quarter allow both the optimal-price and compromise models to deliver a much broader range of prices, which closely resemble observations. 

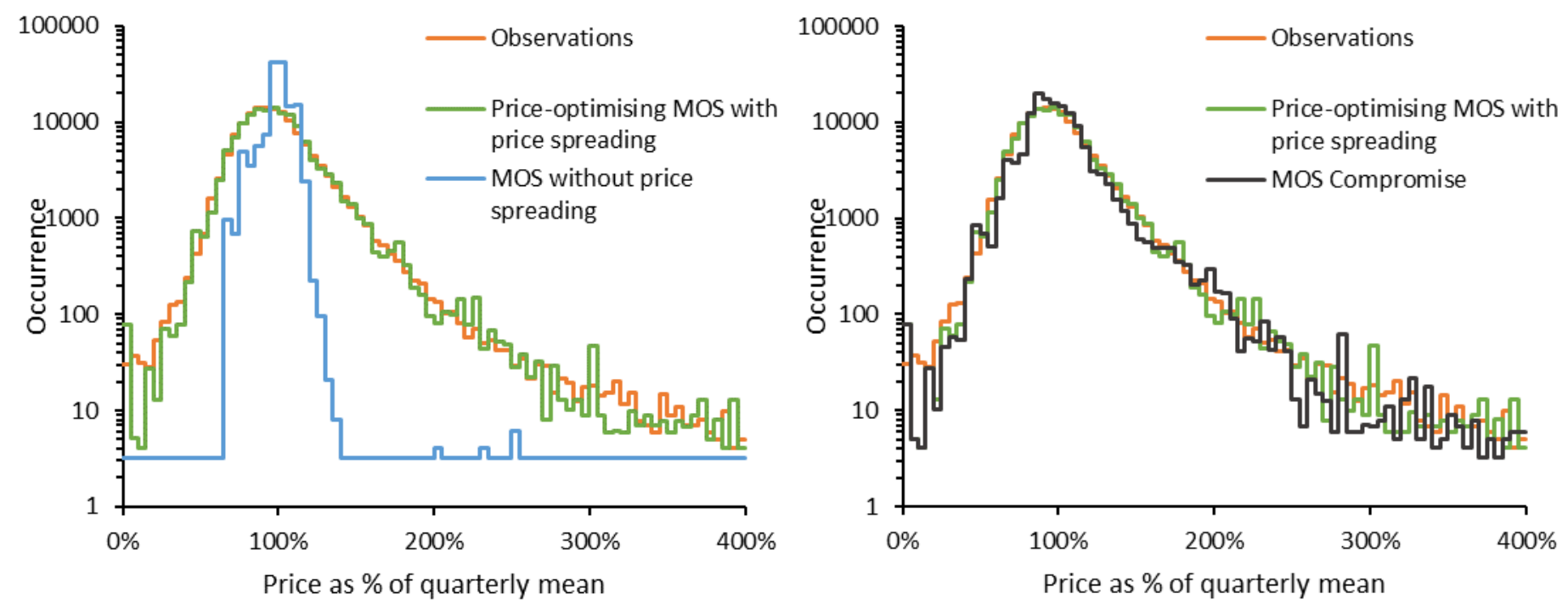

Figure 10: Histogram of prices for the entire period 2009-2016. Note the logarithmic scale on the y-axis. The left-hand plot compares the distribution of observed prices with those obtained from the basic MOS model with no spreading and the price-optimised model. The right-hand plot also shows the compromise model. Results for individual quarters may be found in the supplementary material.

Figure 11 demonstrates the skill of the MOS with spreading approach in recreating the empirical supply curve characteristics in four quarters (full results are presented in the supplementary material). Both the black and orange curves (price-optimal and compromise parameters) show very good agreement with the empirical supply curve. By contrast, and as expected, the basic MOS model (No Spread) exhibits very little variation of price with demand. The model which was optimised for output agreement generally shows a greater range of prices than the basic model, though as seen in 2011 Q4 for example, the supply curve is not always correctly positioned. Quarterly versions of these plots are available in the supplementary material (Figure S1), where differences between their behaviours is examined. 


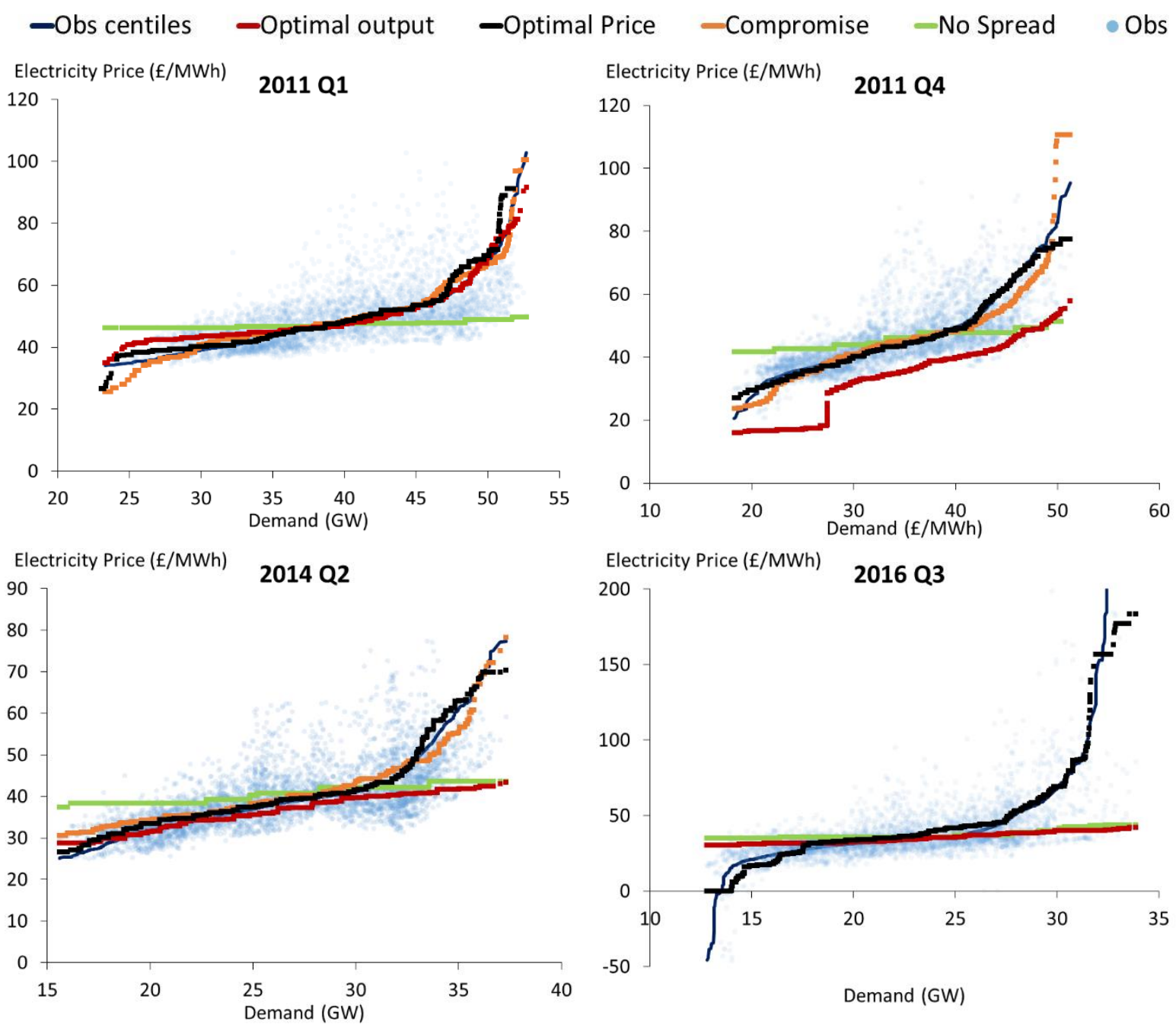

Figure 11: Comparison of the supply curves generated by each of the MOS model formulation, showing prices against demand net of renewables for four quarters. The empirical supply curve (labelled: obs centiles) and the observed prices (cloud of points) are also shown. In some plots the price-optimised and compromise MOS are identical - in this case only the black line is visible.

Finally, with reference back to Figure 1 , we show equivalent diurnal price variability plots for the new models. It should be noted, however, that Figure 1 refers to a single year of prices, whereas Figure 12 is the mean over the 2009-2016 study period, which will tend to make the latter somewhat smoother. The addition of price spreading results in a diurnal pattern of prices that matches much more closely that which is observed. 

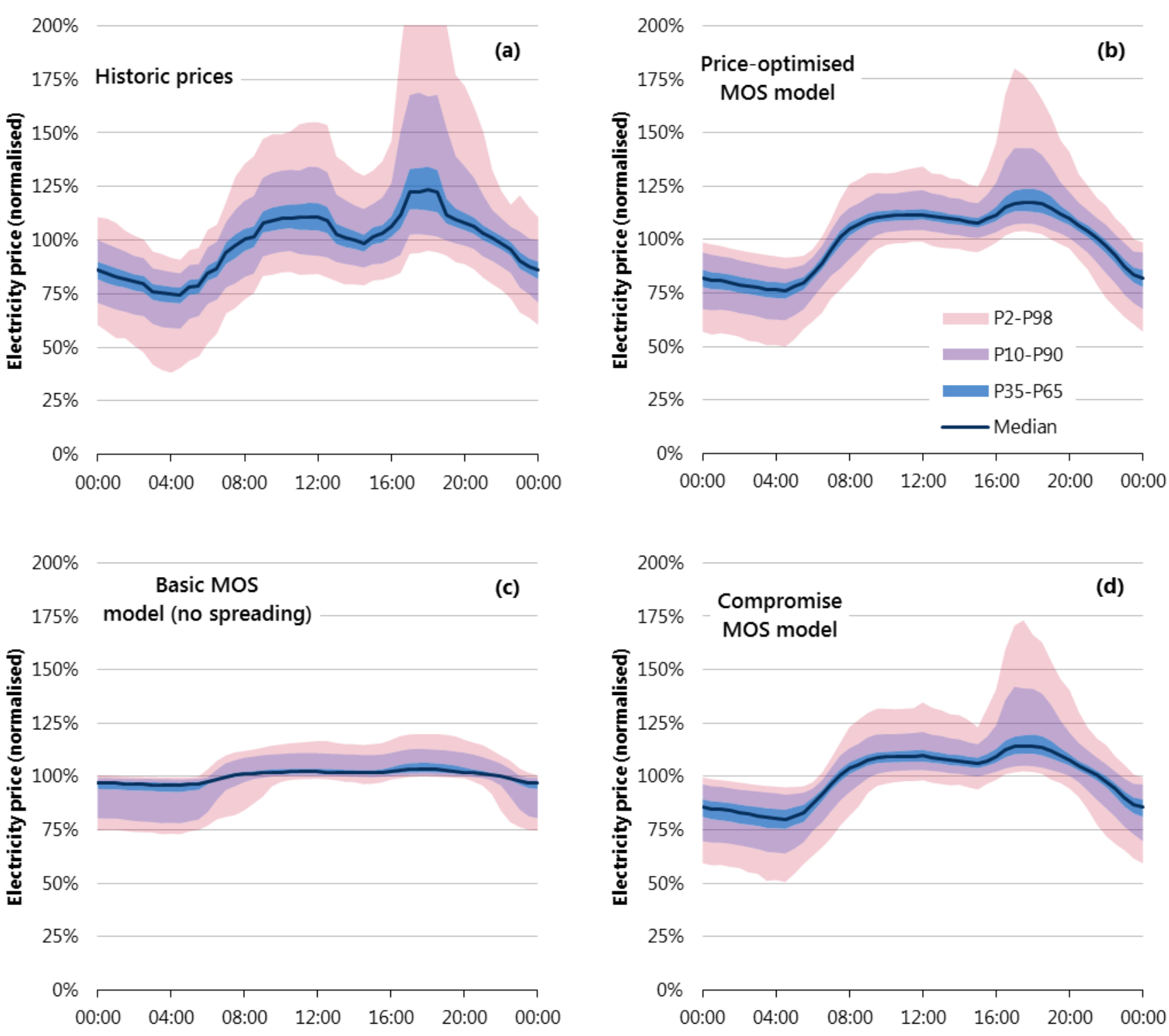

Figure 12: Intra-day normalised price variability (mean over 2009-2016) for observed, price-optimised MOS, MOS without spreading and the compromise MOS model

\subsection{Benchmarking Model Output Prediction Performance}

The main emphasis of this paper is on electricity prices. However, the MOS model also produces predictions for plant dispatch and therefore outputs, and the accuracy of these provides an insight into the validity of the modelling approach. Figure 13, Figure 14 and Table 3 compare the quarterly mean coal and gas outputs and carbon emissions from the no-spreading, priceoptimising, output-optimising and compromise approaches with the observed behaviour of the UK market over the period 2009-2016. 
The MOS model without spreading does not do a convincing job in reproducing the correct mix of generators, consistently over-predicting the usage of coal at the expense of gas. This means that it over-predicts the carbon emissions over the period. It does however correctly discern whether coal or gas is the baseload generator, though the lack of spread within the modelled coal and gas plant 'bids' means that the contribution made by the baseload generator-type is always over-estimated, whilst that of the two-shifting generator is always under-estimated. This is most starkly demonstrated in the output for Q3 2016, where all the demand may be met by the cheaper CCGTs alone, and the model dispatches no coal plant. All the MOS models with spreading improve on this basic situation. The model that is optimised to match output recreates the quarterly mean patterns of coal and gas use almost perfectly. The price-optimised model struggles to pick the correct base-load generator in the early years of the simulation. This situation is rectified to a certain extent by the compromise model, though, as mentioned earlier, the first few quarters represent an area where further improvement in this approach is required.

\begin{tabular}{lccccc}
\hline Metric & $\begin{array}{c}\text { Observed } \\
\text { Output }\end{array}$ & $\begin{array}{c}\text { No } \\
\text { Spreading }\end{array}$ & $\begin{array}{c}\text { Price- } \\
\text { Optimising }\end{array}$ & $\begin{array}{c}\text { Output- } \\
\text { Optimising }\end{array}$ & Compromise \\
\hline Mean quarterly coal output & 24.0 & 29.9 & 25.9 & 23.9 & 24.5 \\
Mean quarterly gas output & 27.9 & 22.0 & 26.0 & 28.0 & 27.4 \\
Mean quarterly carbon emissions & 34.0 & 36.1 & 34.7 & 33.5 & 33.9 \\
RMSE quarterly coal output & - & 9.8 & 4.8 & 0.8 & 2.5 \\
RMSE quarterly gas output & - & 9.8 & 4.8 & 0.6 & 2.5 \\
RMSE quarterly carbon emissions & - & 4.2 & 2.8 & 0.7 & 1.6 \\
\hline
\end{tabular}

Table 3: Measures of the predictive performance of plant utilisation (in TWh per quarter) and carbon emissions (in $\mathrm{Mt} \mathrm{CO}_{2}$ per quarter) from the basic, price-optimising, output-optimising and compromise MOS models. RMSE = root mean square error 
a: MOS model without price spreading

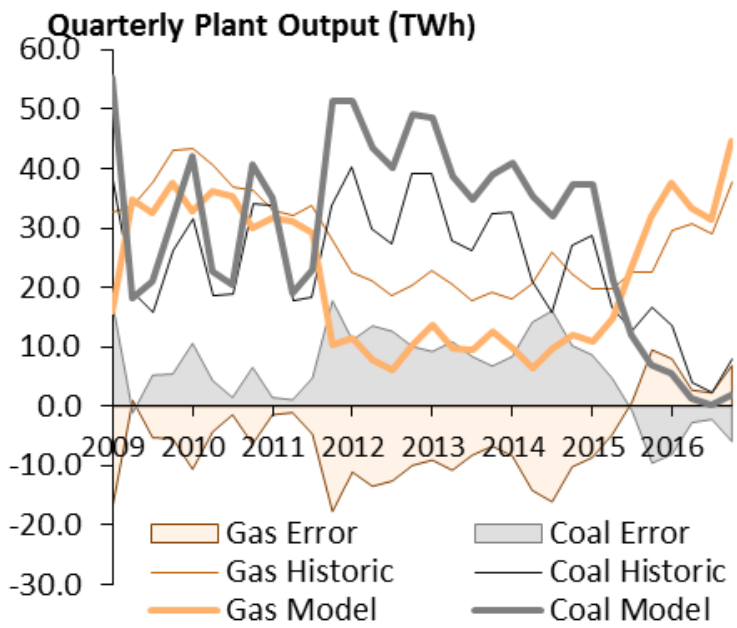

c: Output-optimised price-spreading MOS model Quarterly Plant Output (TWh)

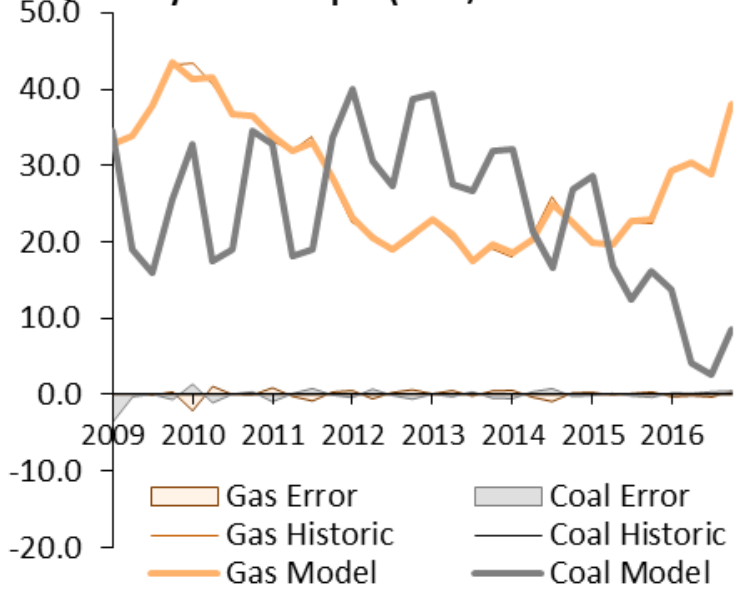

b: Price-optimised price spreading MOS model Quarterly Plant Output (TWh)

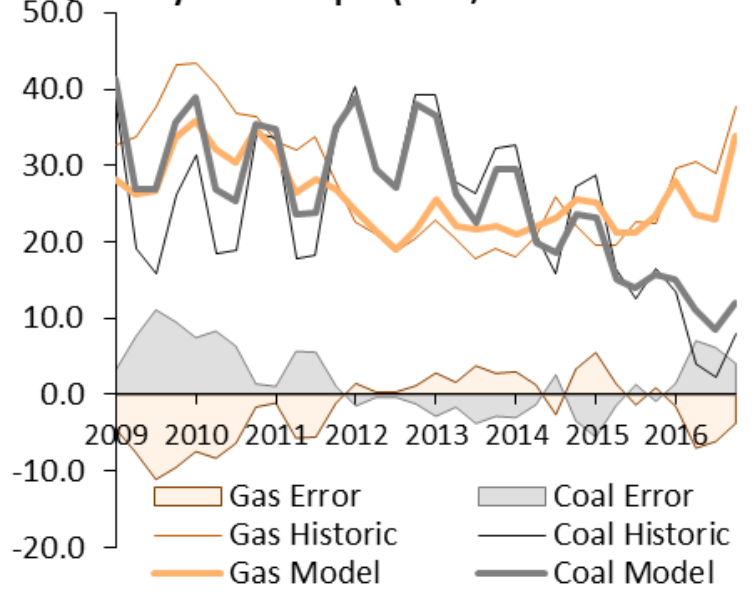

d: Compromise price spreading MOS model Quarterly Plant Output (TWh)

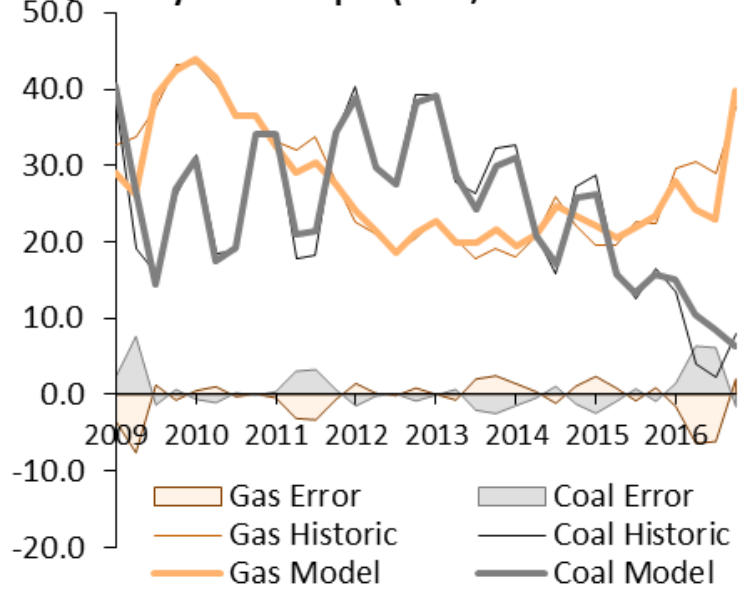

Figure 13: Comparison of the quarterly gas and coal outputs (TWh) from the 4 variants of MOS model with the actual outputs for the period 2009 - 2016. The discrepancy between model and observation is shown by the shaded areas around the origin. 
a: MOS model without price spreading

Modelled output (TWh)

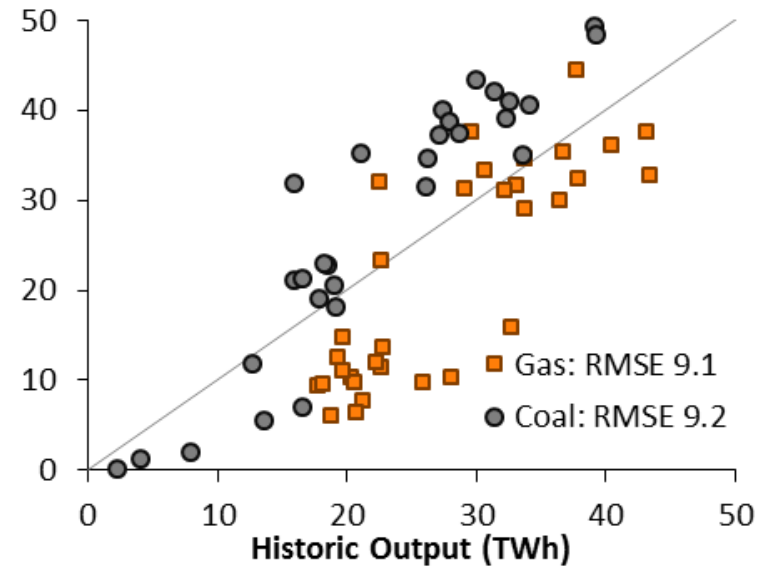

c: Output-optimised price-spreading MOS model Modelled output (TWh)

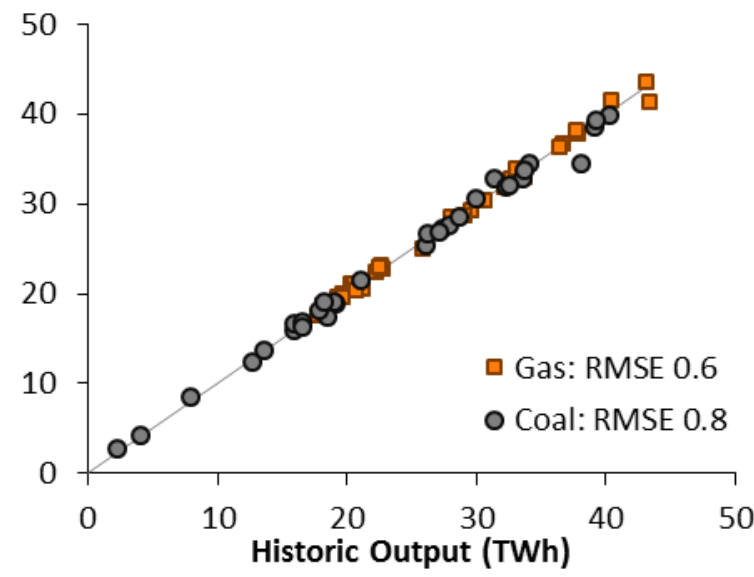

b: Price-optimised price spreading MOS model Modelled output (TWh)

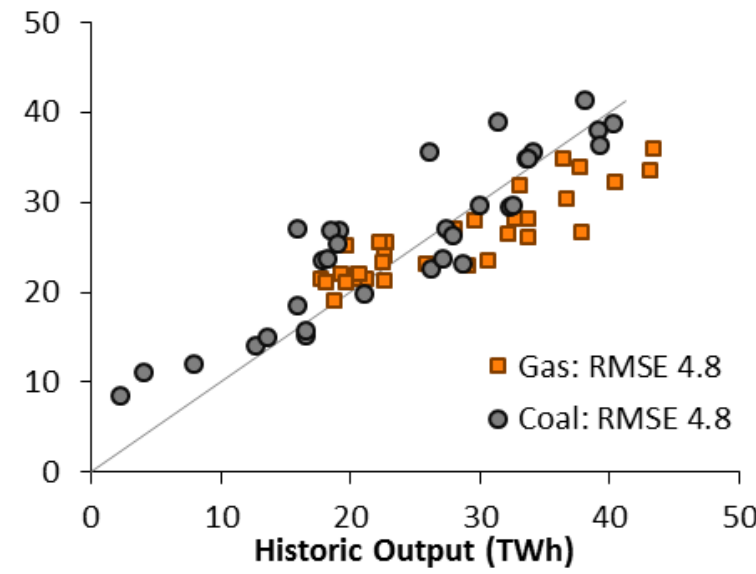

d: Compromise price spreading MOS model Modelled output (TWh)

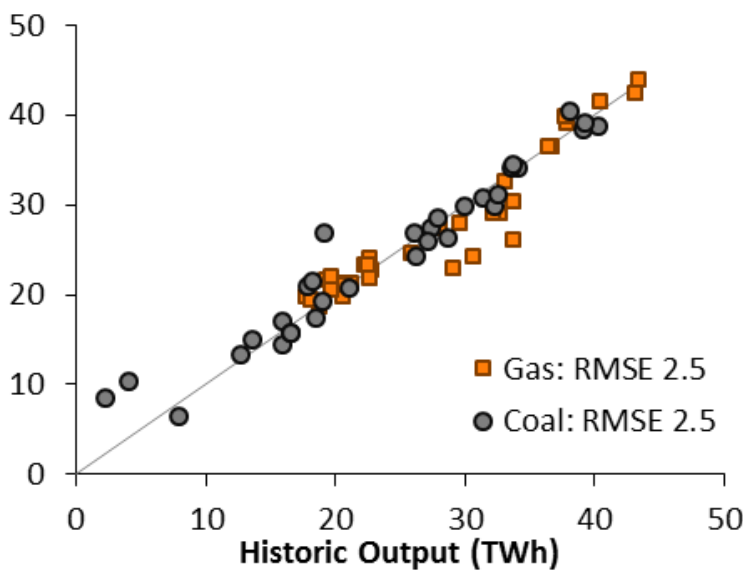

Figure 14: Correlations between the observed and modelled gas and coal energy outputs for the four sets of model parameters shown in Figure 13.

Figure 15 shows the observed volume of CCGT dispatched versus the observed volume of coal dispatched in the UK market for four sample quarters (A complete set of plots for all quarters is given in the supplementary material). The pale blue dots represent the half-hourly values, the dark blue line plots centiles of the distribution of CCGT power versus those for coal. It shows that CCGT and coal-fired power stations are largely dispatched in tandem; in some quarters (e.g. Q4 2012) the observations indicate that coal plant were preferentially dispatched, while in others (e.g. Q4 2016) gas plant tend to be dispatched first. The basic MOS approach (green lines) typically produces patterns of plant usage in which either nearly all the coal plant is dispatched before any of the CCGT is used (Q4 2012, Q2 2014) or vice versa (Q4 2015, Q4 2016); there is little inter-leaving of the generator types within the stack produced in this model (see Figure 4). Modifying the MOS approach to allow bid price spreading (black, red and orange lines) 
reproduces the inter-leaving of the generator types - Figure 6 coal and gas stations 'bidding' across an over-lapping range of prices - as observed in the observed price and dispatch data. In general, the modified model outputs do a good job of replicating the observed centile behaviour, with the output-optimised model clearly doing the best job.
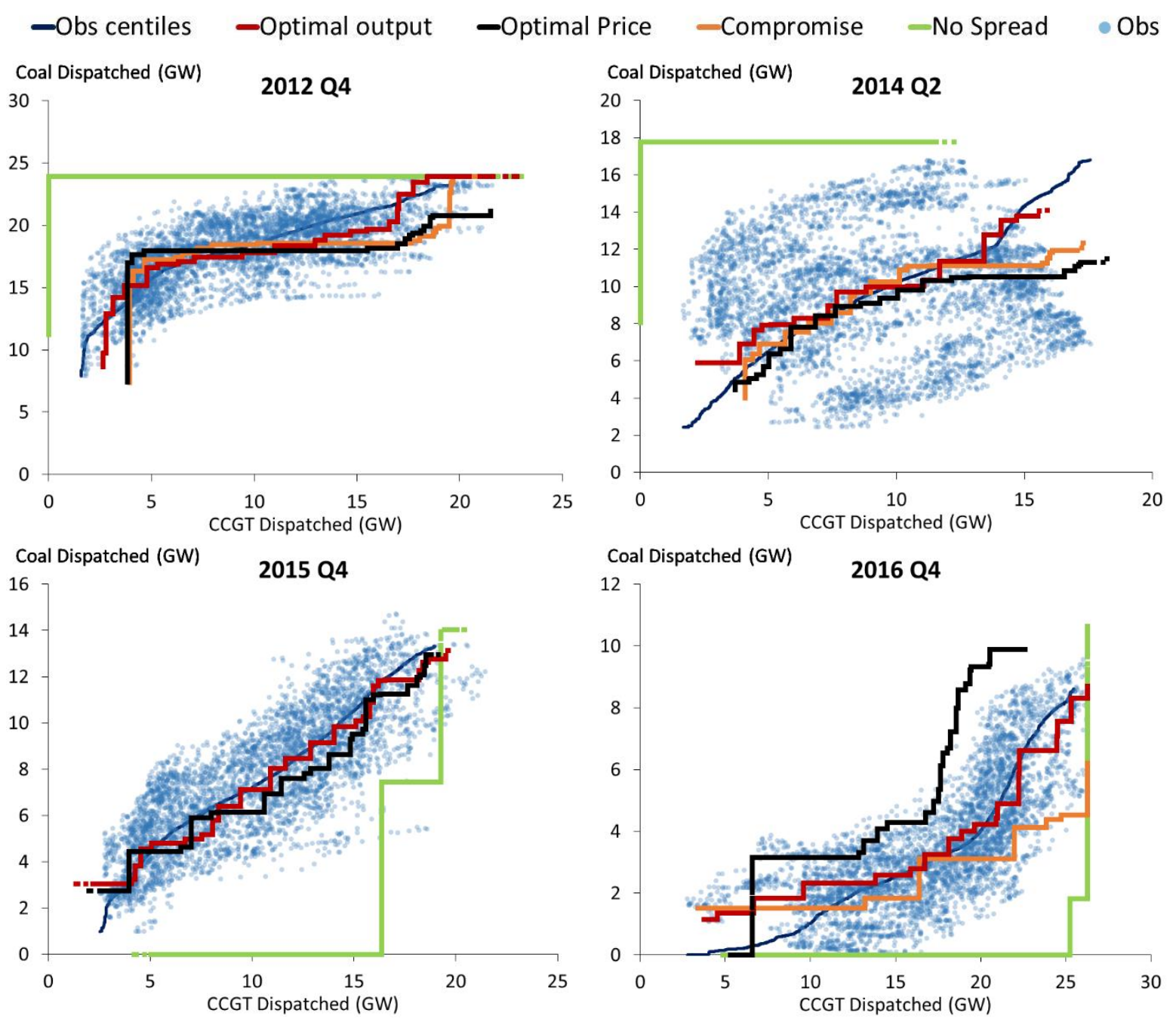

Figure 15: Half-hourly observations of the amount of CCGT versus the amount of coal generation over four quarters. The dark blue line plots CCGT-use centiles against coal-use centiles to show the 'average' behaviour. The green, red, orange and black lines plot the same but for MOS-without-spreading, outputoptimised MOS, compromise-MOS and price-optimised MOS respectively. In some plots the priceoptimised and compromise MOS are identical - in this case only the black line is visible.

The output for Q2 2014 illustrates one short-coming, unavoidable with this approach, which is the inadequacy in some quarters of representing the observed pattern of gas versus coal usage with a single line. All of the modified MOS models do a reasonable job of following the 'Observed Centile' line, however, in this quarter, the 'Observed Centile' line is not representative 
of the far more diverse behaviour of the system. ${ }^{2}$ These plots for all quarters we studied are available in the supplementary material (Figure S2).

\subsection{Small Storage Device Arbitrage Earnings}

Figure 16 shows the maximum quarterly revenues from arbitrage that small storage devices (1MW maximum power flow) using three different battery technologies: (Lithium ion, sodiumsulphur and redox flow) would have earned in the UK electricity market over the period 2009 2016. The mean annual profits are also given in Table 4. Results are shown both as earnings per $\mathrm{MWh}$ of energy storage capacity, per MW of maximum storage power output and as a percentage of the value obtained from the observed price time series. The mean value across all 32 quarters is shown, along with the $10^{\text {th }}$ and $90^{\text {th }}$ centiles to give an indication of inter-quarter variability. Over most of the range of spreading values, the plots show a clear linear relationship between the amount of variability in the time-series of prices and the potential for earning profit through arbitrage. The curves level off as they approach the $x$-axis, reflecting the impact of round trip efficiency on the arbitrage process. Thus the least efficient storage technology (Redox-Flow) requires higher levels of price volatility in order for profitable arbitrage opportunities to arise and even at price-spreading factors of 0.4 there are some quarters in which no such possibilities arise. The upturn at very low values of spreading is due to the breakdown of the relationship between price spreading and standard deviation of prices in a few quarters.

\footnotetext{
${ }^{2}$ This quarter had some periods in which coal stations were on baseload (compare the upper points in the graph for 2014 Q2 with those for 2012 Q4) and some in which gas stations took over this role (compare the lower points with those for 2016 Q4). This switch will have been driven by changing fuel and carbon prices during the quarter - using monthly or daily fuel prices (if they were available opensource) would likely produce a better fit.
} 
Lithium Ion

\section{$86 \%$ efficient; $3 \mathrm{hr}$ discharge}

P10 - P90 range

Mean quarterly earnings

Quarterly earnings (£k/MW)
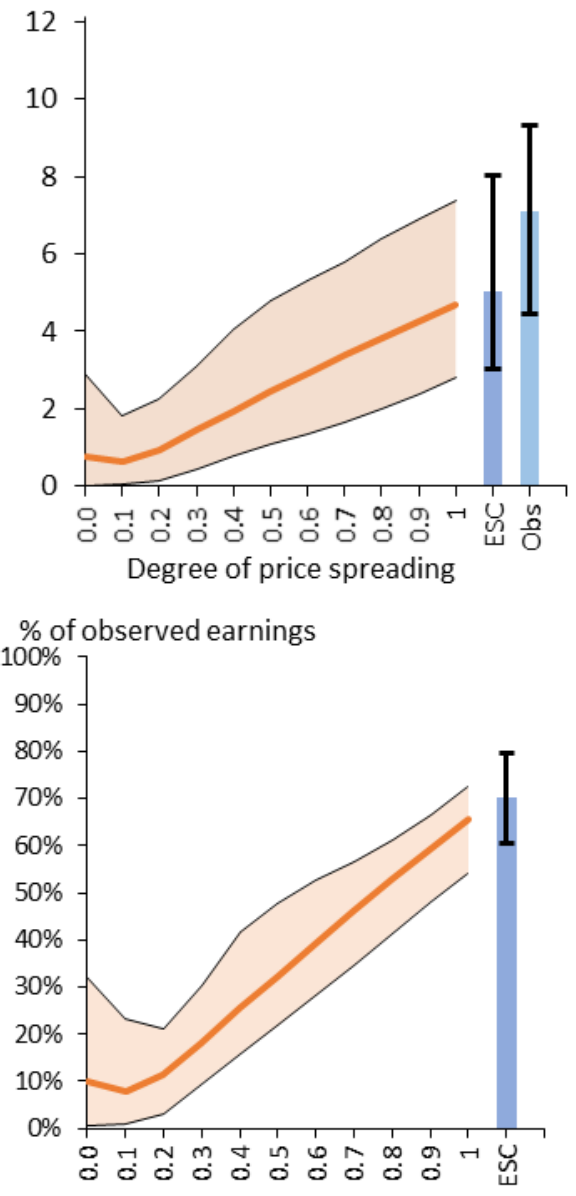

Degree of price spreading
Sodium-Sulphur

81\% efficient; 7 hr discharge P10-P90 range

Mean quarterly earnings

Quarterly earnings ( $\mathrm{k} / \mathrm{MW}$ )

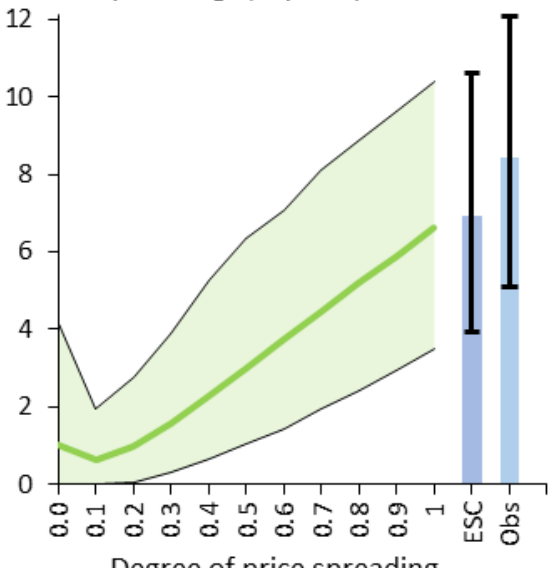

Degree of price spreading

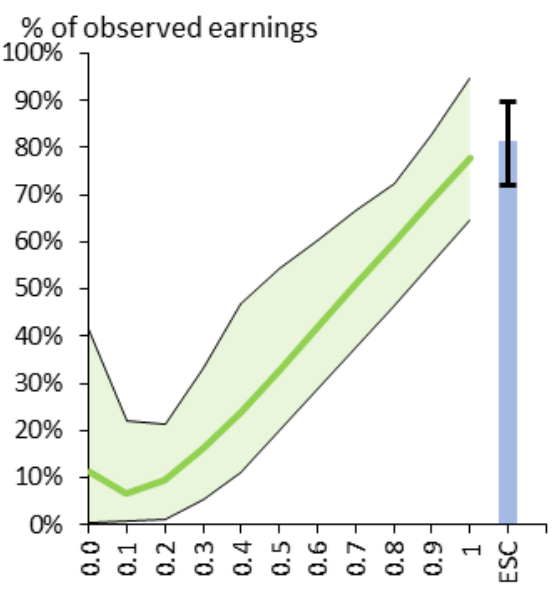

Degree of price spreading
Redox-Flow

73\% efficient; $6 \mathrm{hr}$ discharge P10 - P90 range

-Mean quarterly earnings
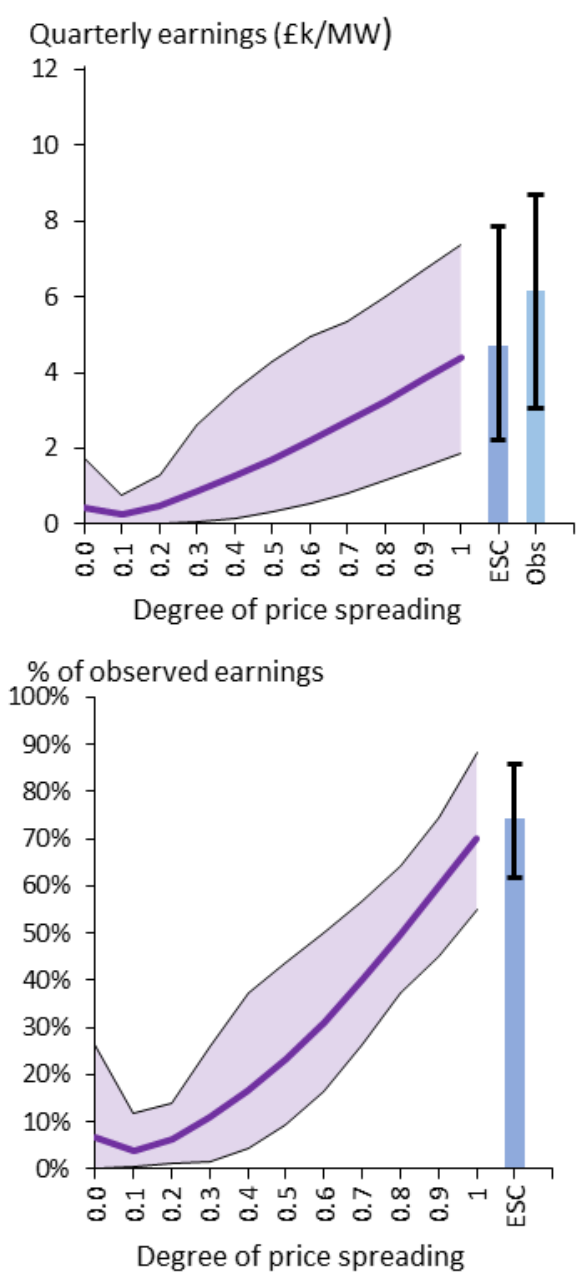

Figure 16: Comparison of the maximum arbitrage profits of 1MW storage devices when deployed against modelled price time-series with varying levels of volatility. The lines represent the mean quarterly profit obtained over the time period 2009-2016. The shaded areas give the $10^{\text {th }}$ to $90^{\text {th }}$ centile ranges. The bars give the profits obtained when using the empirical supply curve and observed market prices, with error bars giving the P10-P90 range. The top row expresses the profits per MW of energy storage potential. The bottom row gives the profits as a percentage of those obtained from the actual observed time-series of prices. 


\begin{tabular}{|c|c|c|c|c|c|c|c|c|c|}
\hline \multirow[b]{2}{*}{$\begin{array}{l}\text { Spreading } \\
\text { parameter }\end{array}$} & \multicolumn{3}{|c|}{ Lithium Ion Profit } & \multicolumn{3}{|c|}{ Sodium-Sulphur Profit } & \multicolumn{3}{|c|}{ Redox-flow Profit } \\
\hline & $£ / \mathbf{k W}$ & f/kWh & $\begin{array}{l}\% \text { of } \\
\text { obs. }\end{array}$ & $£ / \mathbf{k W}$ & f/kWh & $\begin{array}{l}\% \text { of } \\
\text { obs. }\end{array}$ & $£ / \mathbf{k W}$ & E/kWh & $\begin{array}{l}\% \text { of } \\
\text { obs. }\end{array}$ \\
\hline 0.0 & 3.09 & 1.03 & $28.3 \%$ & 4.13 & 0.59 & $32.2 \%$ & 1.80 & 0.30 & $24.2 \%$ \\
\hline 0.1 & 2.58 & 0.86 & $32.5 \%$ & 2.63 & 0.38 & $23.5 \%$ & 1.08 & 0.18 & $12.8 \%$ \\
\hline 0.2 & 3.77 & 1.26 & $44.1 \%$ & 4.01 & 0.57 & $29.8 \%$ & 1.97 & 0.33 & $16.1 \%$ \\
\hline 0.3 & 5.76 & 1.92 & $55.2 \%$ & 6.43 & 0.92 & $42.5 \%$ & 3.49 & 0.58 & $23.6 \%$ \\
\hline 0.4 & 7.80 & 2.60 & $61.8 \%$ & 9.17 & 1.31 & $56.4 \%$ & 5.09 & 0.85 & $32.8 \%$ \\
\hline 0.5 & 9.76 & 3.25 & $65.7 \%$ & 12.06 & 1.72 & $67.3 \%$ & 6.80 & 1.13 & $44.4 \%$ \\
\hline 0.6 & 11.64 & 3.88 & $68.8 \%$ & 14.95 & 2.14 & $75.1 \%$ & 8.72 & 1.45 & $56.9 \%$ \\
\hline 0.7 & 13.52 & 4.51 & $71.6 \%$ & 17.89 & 2.56 & $81.4 \%$ & 10.84 & 1.81 & $67.1 \%$ \\
\hline 0.8 & 15.33 & 5.11 & $73.7 \%$ & 20.78 & 2.97 & $86.9 \%$ & 13.01 & 2.17 & $75.5 \%$ \\
\hline 0.9 & 17.08 & 5.69 & $75.0 \%$ & 23.65 & 3.38 & $91.8 \%$ & 15.25 & 2.54 & $82.7 \%$ \\
\hline 1 & 18.77 & 6.26 & $76.1 \%$ & 26.48 & 3.78 & $95.8 \%$ & 17.52 & 2.92 & $89.1 \%$ \\
\hline ESC & 20.05 & 6.68 & $76.6 \%$ & 27.76 & 3.97 & $96.6 \%$ & 18.78 & 3.13 & $89.0 \%$ \\
\hline Historic & 28.48 & 9.49 & $100 \%$ & 33.80 & 4.83 & $100 \%$ & 24.69 & 4.12 & $100 \%$ \\
\hline
\end{tabular}

Table 4: Summary of mean annual profits from arbitrage for three storage technologies, per unit of power and energy capacity. Rows show the results as derived from modelled time-series of prices with varying volatility, and with price obtained from an empirical supply curve (ESC) and historical prices.

The headline metrics for the price-optimised model indicate that it does a very good job of reproducing the observed prices within the UK market over this period. Even so, the time series of prices with full price spreading only capture $66 \%, 78 \%$ and $70 \%$ of the arbitrage earnings available for a lithium ion, sodium-sulphur and redox-flow storage device respectively. The MOS with no price spreading, which also accurately discerns the mean price over the period 2009-2016 (Table 2) predicts arbitrage profits that are only $10 \%$ of those that the observed prices produce.

The straight-line relationship between spreading/standard deviation and arbitrage values suggests that it might be possible to estimate the true levels of arbitrage earnings based upon the output from a model with insufficiently variable prices. If the gradients of the lines in Figure 16 can be reliably related to the efficiency and discharge time of a storage device then, provided that the store is small and therefore that its use will not affect the market, this would provide a useful method for correcting the errors introduced by inaccurate price variability. This is the subject of on-going work.

\subsection{Small storage device utilisation}

The distribution of prices not only affects the profits available to a storage device through arbitrage, it also impacts on the how much the device is used. With round trip efficiencies of less than $100 \%$, arbitrage transactions in which the profit to be made would be eliminated due to inefficiency (i.e. those with smaller price differentials) will not take place. This means that for 
time-series in which price variability is under-estimated, so too will be the storage device utilisation. As the quantity of storage within a system is increased, the knock-on effect of this on the usage of other generators will become significant. Figure 17 and Table 5 show how the utilisation of each technology type is impacted by changes in price variability. Utilisation is defined as the absolute value of storage input/output divided by maximum storage power, averaged over the quarter.

The performance of the MOS with full spreading as compared to the observed prices improves as the maximum length of discharge increases. This reflects the fact that the observed prices exhibit greater levels of volatility on short time-scales than does the demand, from which the variability in modelled prices is derived. The shorter window for energy transfers afforded by the lithium ion storage is more sensitive to this, hence the MOS (and empirical supply curve) can only achieve $76 \%$ of the observed utilisation.

A shorter re/discharge time gives fewer opportunities for storage operation and therefore lower levels of utilisation, hence the lithium ion store is used least and the sodium-sulphur the most. Inefficiency leads to greater sensitivity to the variability of the underlying prices, with the redox flow storage showing the sharpest decline in utilisation as variability decreases and the lithium ion storage the least.

\section{Lithium Ion} $86 \%$ efficient; $3 \mathrm{hr}$ discharge

P10 - P90 range

-Mean quarterly earnings

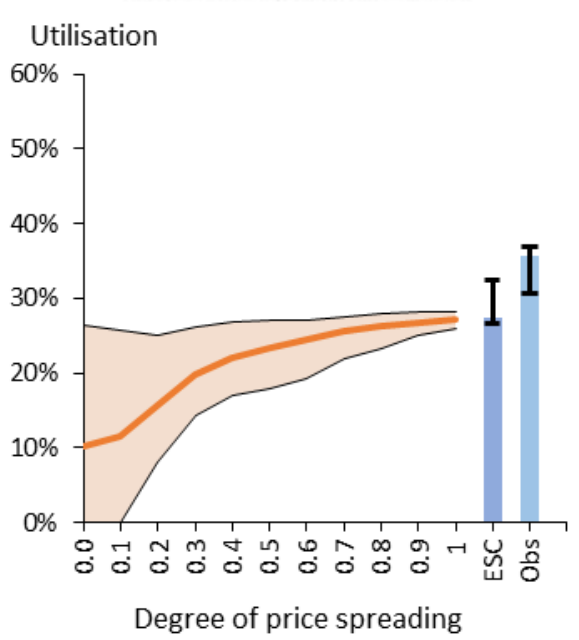

Sodium-Sulphur $81 \%$ efficient; 7 hr discharge P10-p90 range

Mean quarterly earnings

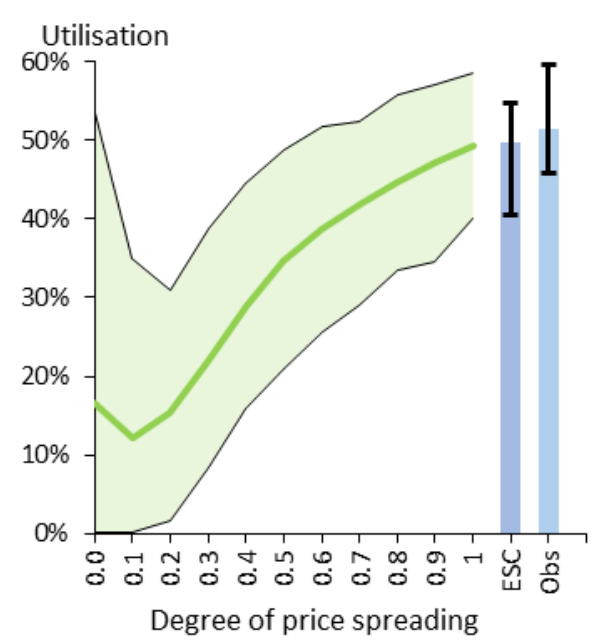

Redox-Flow $73 \%$ efficient; $6 \mathrm{hr}$ discharge P10 - P90 range

-Mean quarterly earnings

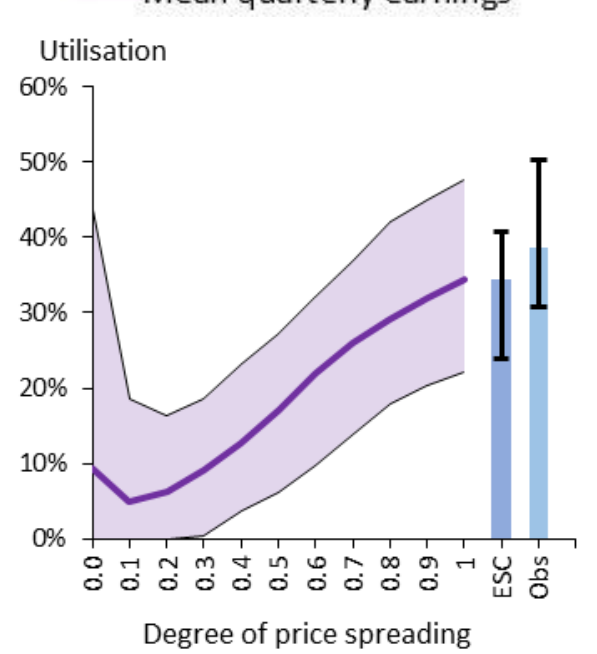

Figure 17: Variation of storage device utilisation with price spreading for each technology type. The lines represent the mean quarterly profit obtained over the time period 2009-2016. The shaded areas give the 
$10^{\text {th }}$ to $90^{\text {th }}$ centile ranges. The bars give the utilisations obtained when using the empirical supply curve and observed market prices, with the error bars giving the P10-P90 range.

\begin{tabular}{|c|c|c|c|c|c|c|}
\hline \multirow{2}{*}{$\begin{array}{l}\text { Spreading } \\
\text { parameter }\end{array}$} & \multicolumn{2}{|c|}{$\begin{array}{l}\text { Lithium Ion } \\
\text { Utilisation }\end{array}$} & \multicolumn{2}{|c|}{$\begin{array}{c}\text { Sodium-Sulphur } \\
\text { Utilisation }\end{array}$} & \multicolumn{2}{|c|}{$\begin{array}{l}\text { Redox-flow } \\
\text { Utilisation }\end{array}$} \\
\hline & (\%) & $\begin{array}{l}\% \text { of } \\
\text { obs }\end{array}$ & (\%) & $\begin{array}{l}\% \text { of } \\
\text { obs }\end{array}$ & (\%) & $\begin{array}{c}\% \text { of } \\
\text { obs }\end{array}$ \\
\hline 0.0 & $10.1 \%$ & $28.3 \%$ & $16.6 \%$ & $32.2 \%$ & $9.3 \%$ & $24.2 \%$ \\
\hline 0.1 & $11.6 \%$ & $32.5 \%$ & $12.1 \%$ & $23.5 \%$ & $4.9 \%$ & $12.8 \%$ \\
\hline 0.2 & $15.8 \%$ & $44.1 \%$ & $15.3 \%$ & $29.8 \%$ & $6.2 \%$ & $16.1 \%$ \\
\hline 0.3 & $19.7 \%$ & $55.2 \%$ & $21.9 \%$ & $42.5 \%$ & $9.1 \%$ & $23.6 \%$ \\
\hline 0.4 & $22.1 \%$ & $61.8 \%$ & $29.0 \%$ & $56.4 \%$ & $12.7 \%$ & $32.8 \%$ \\
\hline 0.5 & $23.5 \%$ & $65.7 \%$ & $34.6 \%$ & $67.3 \%$ & $17.1 \%$ & $44.4 \%$ \\
\hline 0.6 & $24.6 \%$ & $68.8 \%$ & $38.6 \%$ & $75.1 \%$ & $22.0 \%$ & $56.9 \%$ \\
\hline 0.7 & $24.6 \%$ & $71.6 \%$ & $41.9 \%$ & $81.4 \%$ & $25.9 \%$ & $67.1 \%$ \\
\hline 0.8 & $25.6 \%$ & $73.7 \%$ & $44.7 \%$ & $86.9 \%$ & $29.2 \%$ & $75.5 \%$ \\
\hline 0.9 & $26.3 \%$ & $75.0 \%$ & $47.2 \%$ & $91.8 \%$ & $31.9 \%$ & $82.7 \%$ \\
\hline 1 & $26.8 \%$ & $76.1 \%$ & $49.3 \%$ & $95.8 \%$ & $34.4 \%$ & $89.1 \%$ \\
\hline ESC & $27.2 \%$ & $76.6 \%$ & $49.7 \%$ & $96.6 \%$ & $34.4 \%$ & $89.0 \%$ \\
\hline Historic & $27.4 \%$ & $100 \%$ & $51.4 \%$ & $100 \%$ & $38.6 \%$ & $100 \%$ \\
\hline
\end{tabular}

Table 5: Summary of effects of price spreading on storage device utilisation

\subsection{Limitations of the supply curve approach}

The supply curve approach attempts to capture the key short-term features of a complex, multivariable stochastic system using a small number of quarterly-averaged pieces of data in a deterministic formulation. This inevitably introduces unavoidable short-comings and limitations.

The supply curve approach is deterministic: the highest residual demands must give the highest prices, the lowest demands the lowest prices. Thus the high prices predicted by the model will always occur in the late afternoon peak and the lowest prices will always occur at night. On average, as the results show, this works well. However, scrutiny of the observed data shows that this pattern does not match the observed occurrence of price extremes, with the underlying causes of extreme prices being the stochastic processes that were highlighted in Figure 2. It is obviously incorrect to reproduce these extremes in this way and then to allow the arbitrage to capture the value from them since it is the unexpected nature of the event that causes the price spikes and the storage owner would therefore be unable to schedule for it. This will lead to an over-estimation of the arbitrage earnings by this method. It is estimated by [30] that actual arbitrage earnings would be around $80 \%$ of those predicted. 
The variability in price within any individual quarter of this model is solely linked to the variability in demand. This has two obvious drawbacks. Firstly, where timescales of price volatility differ from timescales of demand volatility these effects cannot be accounted for. This was highlighted in Section 4.4, where none of the demand-based pricing methods was able to match the utilisation levels achieved by the observed price time-series for the lithium ion storage, but performance improved for the longer timescale storage options. The second problem arises where the behaviour of market participants regularly introduces a bi-modal set of prices for the same level of demand. Within the UK market it may be seen that the morning peak prices are lower than the prices in the afternoon, even where the levels of demand are the same. This makes the diurnal demand profile smoother than the corresponding price profile and this method cannot accommodate it without introducing multiple stack formulations - a significant added complication.

Beyond this, there are obviously issues that arise from summarising a whole quarter with a single set of parameters for price and availability. Some quarters (e.g. Q2 2014 in Figure 15) show considerable intra-quarter variability suggesting that while we might capture the mean behaviour, actually this does not apply well to any aspect of the data. These types of issue will always arise where averaging of this occurs. There is only limited scope to address this since the time-scales on which the model works are largely determined by the availability of input data.

\section{Conclusions and Policy Implications}

The variability of the price time-series that are output by structural electricity models has not previously been considered an important metric for gauging model performance, and we have been unable to find any examples of structural market modelling approaches in which this issue is considered. However, levels of power price volatility are increasing as generation is increasingly reliant on weather-based renewable sources. Meanwhile, emerging technologies are widely anticipated to play a crucial role in balancing out these temporal and spatial imbalances, but can only do so if price volatility is sufficient to support their business model.

Modelling can never be perfect, but a systematic failure to represent price volatility in the models used to support policy formation could lead to systemic policy failings, such as in the nature and level of support that should be offered to arbitrage-reliant technologies, or under-expectations 
around the extent to which these technologies could be relied upon in future to balance out intermittent renewables. Understanding the value of flexibility for power systems is an important topic across industry, academia and government [34-36]. For such modelling to reliably inform policymaking about the future of electricity systems, it is imperative that model power price variability is as realistic as possible so that the deployment of storage and interconnectors is accurately captured. In this way both the economics associated with these technologies and the implications of their use for incumbent generators can be correctly assessed.

Our study focusses on the arbitrage earnings from storage, which show a large sensitivity to the price spread and volatility in electricity market prices, with inadequate variability in time-series of modelled prices leads to serious underestimates (Section 4.3). Even with observed prices, the anticipated profits fall far below the levels that would make storage economically viable on these terms (mean annual profits $£ 28.48 / \mathrm{kW}$ compared to CAPEX costs at the level of $£ 800 / \mathrm{kW}$ ). However, if it is accepted that using bulk storage to smooth the residual demand left unmet by zero-emissions sources of generation is essential to the operation of highly-renewable power systems, then dispatching the storage so as to maximise storage profits will maximise the smoothing. Modelled prices that are insufficiently variable will lead to under-estimation of storage utilisation within models and will, therefore, underestimate the potential benefits that storage might bring. The effects of this are most pronounced with less efficient storage technologies and with shorter storage times (Section 4.4).

The possible need for capacity markets or other mechanisms to compensate thermal generators if prices in energy-only markets become inadequate is another area of current debate that can be guided by modelling studies. Again, the spread of prices around the mean is crucial for estimating the actual revenues received by infrequently used plant, and this work suggests that these revenues will be underestimated. Additionally, the impact on thermal generators of operating large volumes of storage would be difficult to gauge with the inaccurate storage dispatch patterns that inadequately varying prices would produce. We would anticipate similar, though lesser, difficulties with the modelling of interconnector profits.

We have developed a new approach to MOS modelling, which offers an improvement by recognising the breadth of bids that similar generators might make (Section 3.3). With careful choice of parameters, the bid-spreading approach is able to closely match the empirical supply 
curve for most of the quarters between 2009 and 2016 (Section 4.1). With some compromises to this 'price-optimised' approach, it is also possible to reproduce the observed outputs of coal and gas aggregated over the quarter (Section 4.2). There is however, still room for improvement. Analysis shows that this approach works much better in some quarters than in others. Further investigation of the parameter space should yield improved parameters in these cases.

We currently optimise the parameters that this model needs for each quarter in turn from the full set of historic price and output data. It might be better if the optimal parameter choices could be related to a small number of variables that are knowable ex ante. This would then allow the approach to be extended so that it could be used to model prices and corresponding outputs in the future, or within other markets, rather than just being a tool for probing alternative histories. Any future methodological advance must be able to:

1. preserve the ability of the model to provide long term signals regarding mean energy pricing and revenue for conventional generators

2. adequately represent the variability so as to generate the correct signals regarding storage devices and their revenues and properties.

In this work we have identified a widespread short-coming in the modelling of wholesale electricity prices which has a significant bearing on the way in which the use of storage (or interconnectors) would be deployed in structural power market models. We have developed an heuristic approach that goes some way towards solving the problem, and anticipate that further work on the theoretical underpinning of the methodology will lead to further improvements. Such work would ideally test this theory across more than one model type, including more technically-rich unit commitment models, and ideally also across more than one market, and may ultimately lead to a generalised method for getting prices right in structural electricity market models.

\section{Acknowledgement}

This work was funded by the Engineering and Physical Sciences Research Council under grant EP/M001369/1. We would like to thank the editor and two anonymous referees for helpful comments. 


\section{References}

[1] Pfenninger S, DeCarolis J, Hirth L, Quoilin S and Staffell I, 2017. The importance of open data and software: Is energy research lagging behind? Energy Policy, 101: 211-215.

[2] Pfenninger S, 2017. Energy scientists must show their workings. Nature, 542(7642): 393-393.

[3] Ringkjob HK, Haugan PM and Solbrekke IM, 2018. A review of modelling tools for energy and electricity systems with large shares of variable renewables. Renewable \& Sustainable Energy Reviews, 96: 440-459.

[4] Green RJ, 2008. Electricity Wholesale Markets: Designs Now and in a Low-carbon Future. Energy Journal, 29: 95-124.

[5] McConnell D, Hearps P, Eales D, Sandiford M, et al., 2013. Retrospective modeling of the meritorder effect on wholesale electricity prices from distributed photovoltaic generation in the Australian National Electricity Market. Energy Policy, 58: 17-27.

[6] Green R, Staffell I and Vasilakos N, 2014. Divide and Conquer? k-Means Clustering of Demand Data Allows Rapid and Accurate Simulations of the British Electricity System. IEEE Transactions on Engineering Management, 61(2): 251-260.

[7] Hirth L, 2018. What Caused the Drop in European Electricity Prices? A Factor Decomposition Analysis. Energy Journal, 39(1): 143-157.

[8] Staffell I, 2017. Measuring the progress and impacts of decarbonising British electricity. Energy Policy, 102: 463-475.

[9] Open Power System Data, 2018. Data Package Time series. Version 2018-03-13. URL: https://data.open-power-system-data.org/time series/2018-03-13/

[10] Ketterer JC, 2014. The impact of wind power generation on the electricity price in Germany. Energy Economics, 44: 270-280.

[11] Boßmann T and Staffell I, 2015. The shape of future electricity demand: Exploring load curves in 2050s Germany and Britain. Energy, 90, Part 2: 1317-1333.

[12] Foley A, Tyther B, Calnan P and Gallachoir BO, 2013. Impacts of Electric Vehicle charging under electricity market operations. Applied Energy, 101: 93-102.

[13] Cooper SJG, Hammond GP, McManus MC and Pudjianto D, 2016. Detailed simulation of electrical demands due to nationwide adoption of heat pumps, taking account of renewable generation and mitigation. Iet Renewable Power Generation, 10(3): 380-387.

[14] Thornton HE, Hoskins BJ and Scaife AA, 2016. The role of temperature in the variability and extremes of electricity and gas demand in Great Britain. Environmental Research Letters, 11(11).

[15] Pfenninger S, 2017. Dealing with multiple decades of hourly wind and PV time series in energy models: A comparison of methods to reduce time resolution and the planning implications of inter-annual variability. Applied Energy, 197: 1-13.

[16] Weron Rł, 2006. Modeling and Forecasting Electricity Loads and Prices: A statistical Approach: John Wiley \&amp; Sons Ltd.

[17] Weron $\mathrm{R}$, 2014. Electricity price forecasting: A review of the state-of-the-art with a look into the future. International Journal of Forecasting, 30(4): 1030-1081.

[18] Hong T, 2014 Energy Forecasting: past, present and future. Foresight: The International Journal of Applied Forecasting, 32(Winter): 43-48. 
[19] Aggarwal SK, Saini LM and Kumar A, 2009. Electricity price forecasting in deregulated markets: A review and evaluation. International Journal of Electrical Power \&amp; Energy Systems, 31(1): 13-22.

[20] Joos M and Staffell I, 2018. Short-term integration costs of variable renewable energy: Wind curtailment and balancing in Britain and Germany. Renewable \& Sustainable Energy Reviews: In Press.

[21] Fanone E, Gamba A and Prokopczuk M, 2013. The case of negative day-ahead electricity prices. Energy Economics, 35: 22-34.

[22] Staffell I and Green R, 2016. Is There Still Merit in the Merit Order Stack? The Impact of Dynamic Constraints on Optimal Plant Mix. Ieee Transactions on Power Systems, 31(1): 43-53.

[23] National Grid, Data Explorer. URL: https://www.nationalgrideso.com/balancing-data/dataexplorerv

[24] Hirst D, 2018. Carbon Price Floor (CPF) and the price support mechanism: House of Commons Library - BRIEFING PAPER Number 05927. URL: http://researchbriefings.parliament.uk/ResearchBriefing/Summary/SN05927

[25] The Intercontinental Exchange (ICE), 2017. EUA Futures - Emissions Index. URL: https://www.theice.com/marketdata/reports/82

[26] Department for Business, Energy and Industrial Strategy, 2017. Quarterly Energy Prices. URL: www.gov.uk/government/collections/quarterly-energy-prices

[27] Bloomberg New Energy Finance, 2018. BNEF Proprietory UK Capacity Database.

[28] Ward KR and Staffell I, 2018. Simulating price-aware electricity storage without linear optimisation. Journal of Energy Storage, 20: 78-91.

[29] Lund H, Salgi G, Elmegaard B and Andersen AN, 2009. Optimal operation strategies of compressed air energy storage (CAES) on electricity spot markets with fluctuating prices. Applied Thermal Engineering, 29(5-6): 799-806.

[30] Connolly D, Lund H, Finn P, Mathiesen BV and Leahy M, 2011. Practical operation strategies for pumped hydroelectric energy storage (PHES) utilising electricity price arbitrage. Energy Policy, 39(7): 4189-4196.

[31] Staffell I and Rustomji M, 2016. Maximising the value of electricity storage. Journal of Energy Storage, 8: 212-225.

[32] Schmidt O, Melchior S, Hawkes A and Staffell I, 2019. Projecting the future levelized cost of electricity storage technologies. Joule, In press.

[33] Hirth L, 2016. The European Electricity Market Model EMMA Model documentation. URL: http://www.neon-energie.de/emma-documentation.pdf

[34] Goutte S and Vassilopoulos P, 2019. The value of flexibility in power markets. Energy Policy, 125: 347-357.

[35] Strbac G, Aunedi M, Pudjianto D, Djapic P, et al., 2012. Strategic Assessment of the Role and Value of Energy Storage Systems in the UK Low Carbon Energy Future. Report for the Carbon Trust.

[36] Boston A, Bongers G, Byrom S and Staffell I, 2017. Managing Flexibility Whilst Decarbonising Electricity - the Australian NEM is changing. Report for ANLEC R\&D. 